\title{
Liquid biopsy and PCR-free ultrasensitive detection systems in oncology (Review)
}

\author{
ALESSIA FINOTTI $^{1}$, MATTEO ALLEGRETTI ${ }^{2}$, JESSICA GASPARELLO $^{1}$, \\ PATRIZIO GIACOMINI ${ }^{2}$, DEMETRIOS A. SPANDIDOS ${ }^{3}$, \\ GIUSEPPE SPOTO $^{4,5}$ and ROBERTO GAMBARI ${ }^{1,6}$ \\ ${ }^{1}$ Department of Life Sciences and Biotechnology, Ferrara University, 44121 Ferrara; \\ ${ }^{2}$ Oncogenomics and Epigenetic Unit, IRCCS Regina Elena National Cancer Institute, \\ 00144 Rome, Italy; ${ }^{3}$ Laboratory of Clinical Virology, Medical School, University of Crete, \\ 71003 Heraklion, Crete, Greece; ${ }^{4}$ Department of Chemistry, Catania University, 95125 Catania; \\ ${ }^{5}$ I.N.B.B. Consortium, c/o Department of Chemistry, Catania University, 95125 Catania; \\ ${ }^{6}$ Interuniversity Consortium for Biotechnology (CIB), 34012 Trieste, Italy
}

Received May 17, 2018; Accepted July 31, 2018

DOI: $10.3892 /$ ijo.2018.4516

\begin{abstract}
In oncology, liquid biopsy is used in the detection of next-generation analytes, such as tumor cells, cell-free nucleic acids and exosomes in peripheral blood and other body fluids from cancer patients. It is considered one of the most advanced non-invasive diagnostic systems to enable clinically relevant actions and implement precision medicine. Medical actions include, but are not limited to, early diagnosis, staging, prognosis, anticipation (lead time) and the prediction of therapy responses, as well as follow-up. Historically, the applications of liquid biopsy in cancer have focused on circulating tumor cells (CTCs). More recently, this analysis has been extended to circulating free DNA (cfDNA) and microRNAs (miRNAs or miRs) associated with cancer, with potential applications for development into multi-marker diagnostic, prognostic and therapeutic
\end{abstract}

Correspondence to: Professor Roberto Gambari, Department of Life Sciences and Biotechnology, Biochemistry and Molecular Biology Section, Ferrara University, Via Fossato di Mortara 74, 44121 Ferrara, Italy

E-mail:gam@unife.it

Abbreviations: CRC, colorectal cancer; HCC, hepatocellular carcinoma; CTCs, circulating tumor cells; cfDNA, circulating free DNA; cfRNA, circulating free RNA; miRNA or miR, microRNA; UTR, untranslated region; CDS, coding sequence; RISC, RNA-induced silencing complex; PCR, polymerase-chain reaction; RT, reverse transcription; qPCR, quantitative PCR; ddPCR, droplet digital PCR; WGS, whole genome sequencing; NGS, next generation sequencing; SPR-I, surface plasmon resonance imaging; SNPs, single nucleotide polymorphisms

Key words: liquid biopsy, circulating tumor cells, circulating free DNA, microRNA signatures. Liquid biopsies avoid some key limitations of conventional tumor tissue biopsies, including invasive tumor sampling, under-representation of tumor heterogeneity and poor description of clonal evolution during metastatic dissemination, strongly reducing the need for multiple sampling. On the other hand, this approach suffers from important drawbacks, i.e., the fragmentation of cfDNA, the instability of RNA, the low concentrations of certain analytes in body fluids and the confounding presence of normal, as well as aberrant DNAs and RNAs. For these reasons, the analysis of cfDNA has been mostly focused on mutations arising in, and pathognomonicity of, tumor DNA, while the analysis of cfRNA has been mostly focused on miRNA patterns strongly associated with neoplastic transformation/ progression. This review lists some major applicative areas, briefly addresses how technology is bypassing liquid biopsy limitations, and places a particular emphasis on novel, PCR-free platforms. The ongoing collaborative efforts of major international consortia are reviewed. In addition to basic and applied research, we will consider technological transfer, including patents, patent applications and available information on clinical trials aimed at verifying the potential of liquid biopsy in cancer.

\section{Contents}

1. The concept of liquid biopsy

2. Analytes in plasma: Examples of biomedical applications

3. Technologies

4. Experimental model systems for technological validation

5. Specific biomedical applications

6. PCR-free detection strategies

7. Patents and clinical trials on liquid biopsy and ultrasensitive detection systems

8. International networks focusing on liquid biopsy

9. Conclusions 


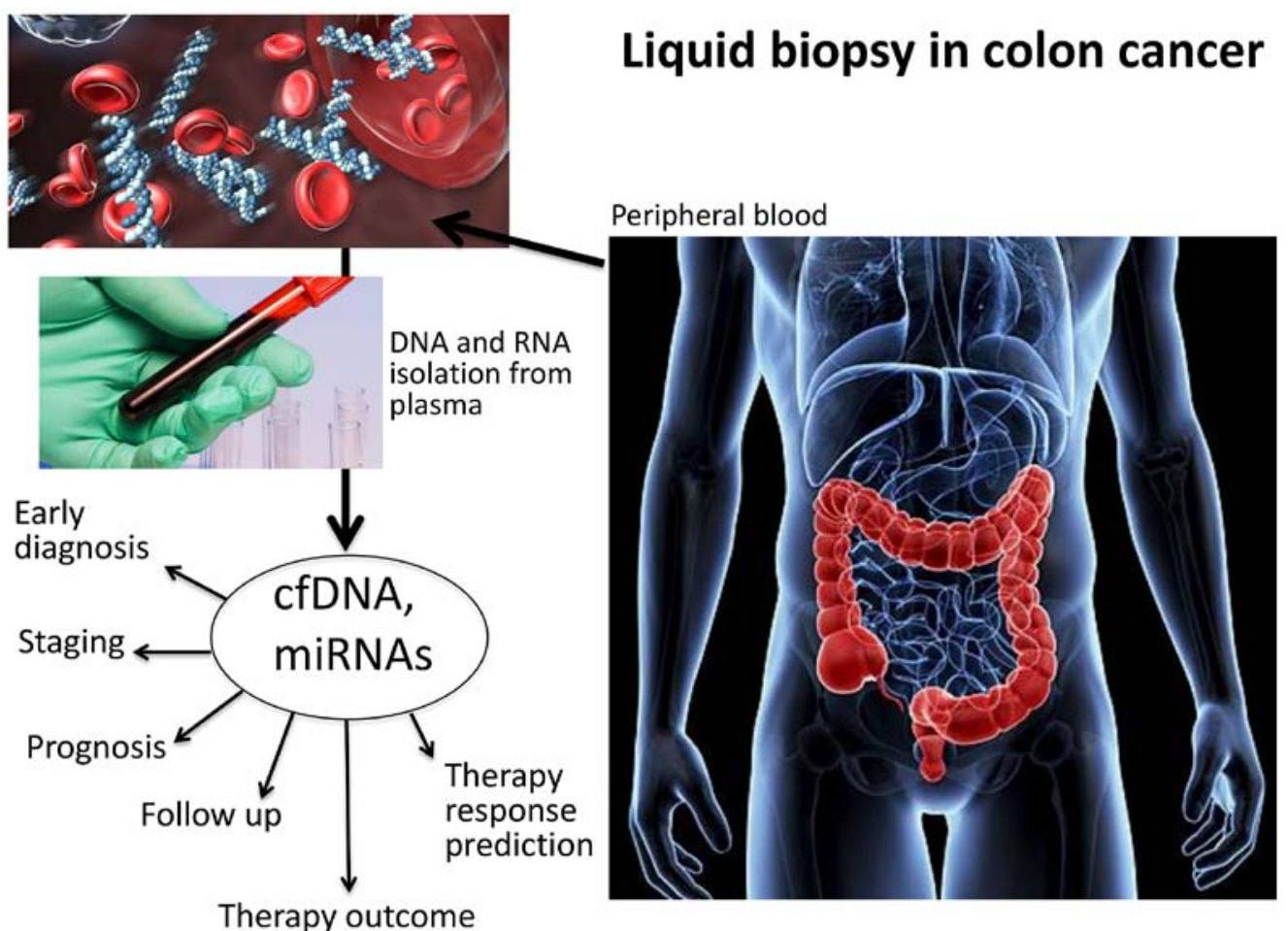

Figure 1. Applications of liquid biopsy in colorectal cancer (CRC)

\section{The concept of liquid biopsy}

Liquid biopsy investigates circulating tumor cells (CTCs) and/ or cell-free nucleic acids in the peripheral blood of cancer patients (Fig. 1) and is considered one of the most advanced non-invasive diagnostic systems with which to obtain key molecular information relevant to clinical decisions and the practice of precision medicine (1-5). Diagnostic actions include, but are not limited to, early diagnosis, staging, prognosis, the prediction of therapeutic responses, and follow-up during therapeutic intervention (5-13). Historically, the applications of liquid biopsy for the characterization of cancer patients have been focused on CTCs (1). Looking for CTCs in peripheral blood has generated a very large number of reports focusing on diagnosis, prognosis and therapeutic management (6). The downstream characterization of CTCs, including the identification of possible therapeutic targets (e.g., mutations or other traits of aggressiveness) in this peculiar tumor cell subset not only has had a great impact on diagnosis and prognostication, but also has an impact on clinical protocols, charting the route to precision medicine (14-16). In this respect, an excellent example is colorectal cancer (CRC), one of the most frequent malignancies worldwide (17). As is known, the transformation of normal colonic epithelium into CRC is punctuated by the progressive accumulation of acquired genetic and epigenetic alterations deeply altering morphological parameters, cell growth potential and differentiation, and shutting down apoptosis. Recent basic and clinical research on CTCs in patients with CRC has underlined that the molecular detection of CTCs in peripheral blood is feasible, and their phenotypic characterization drives therapeutic protocols for tailored clinical interventions (18). Moreover, the real-time monitoring of CTCs in patients with CRC has been extensively applied for a better mechanistic understanding of the factors determining clinical outcome and the efficacy of therapeutic treatment, as well as the stability of therapeutic effects over time (18-21).

In addition to CTCs, the formal demonstration that free nucleic acids are present (although short-lived) in biological fluids (plasma being investigated by most authors), has led to the development of a large wealth of studies aimed at circulating DNA and RNA (22-24). This strategy, similar to CTC detection, allows for non-invasive diagnosis, and at the same time it represents a convenient method for directly interrogating tumor aberrations, addressing tumor heterogeneity and metastatic dissemination across multiple, longitudinally collected clinical specimens $(6,7)$. On the other hand, this approach suffers from important drawbacks, i.e., the fragmentation of circulating free DNA (cfDNA), the instability of RNA, low analyte concentrations, and the confounding, variable presence of DNA and RNA from normal tissues and mutated cells from the hematopoietic compartment (clonal hematopoiesis) (25). Limitations notwithstanding, the analysis of cfDNA has successfully identified mutations arising in, and the pathognomonicity of, tumor DNA, while the analysis of circulating free RNA (cfRNA) has been mostly focused on miRNA patterns strongly associated with neoplastic transformation/progression (22). Examples of the detection of tumor cfDNA are presented in Table I (18-20,26-52), while examples of the detection of circulating miRNAs are presented in Table II (53-104).

\section{Analytes in plasma: Examples of biomedical applications}

Molecular targets: Cancer genetic aberrations. One of the most robust evidence supporting the application value of liquid biopsies is the detection of circulating genomic aberrations, 


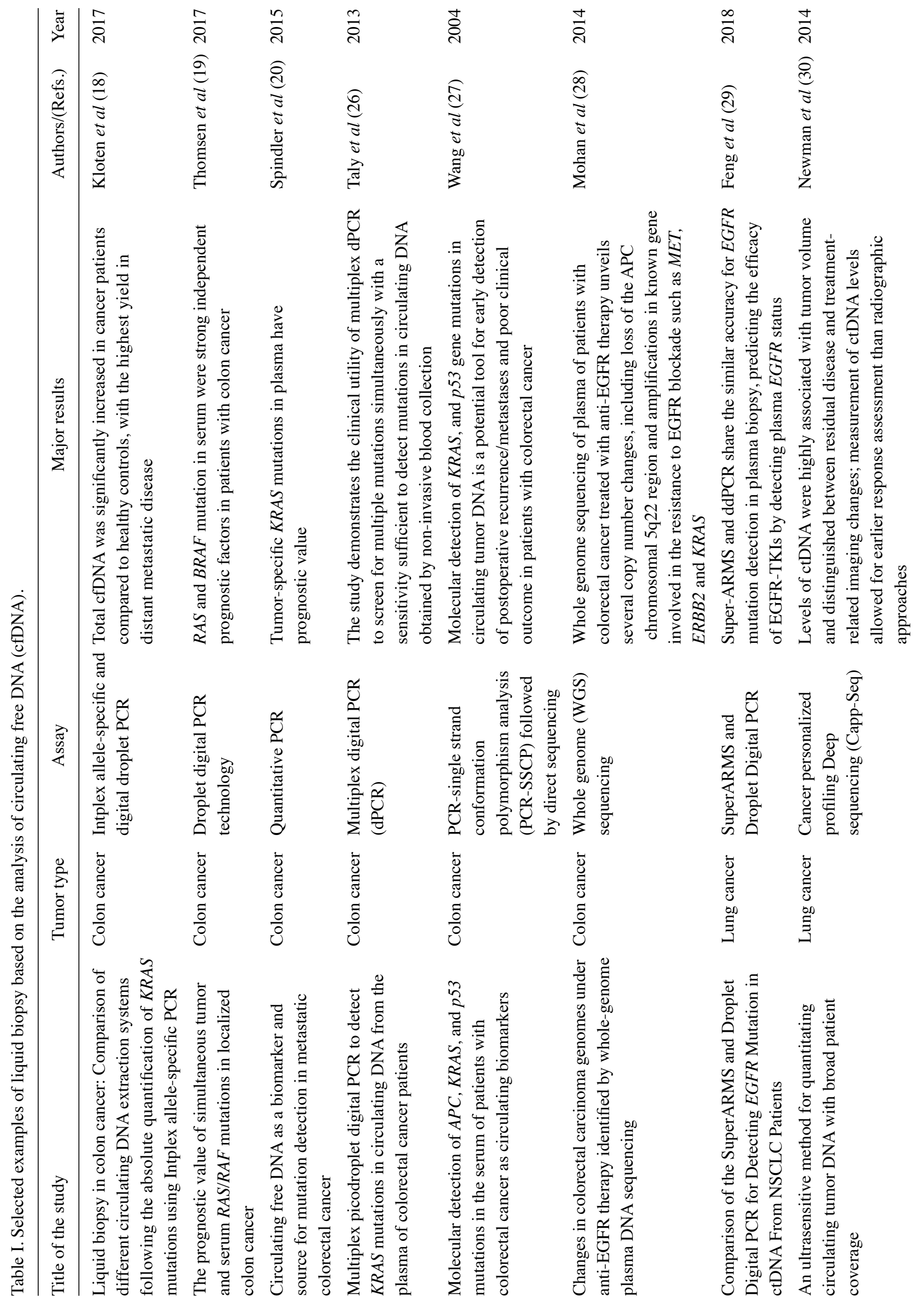




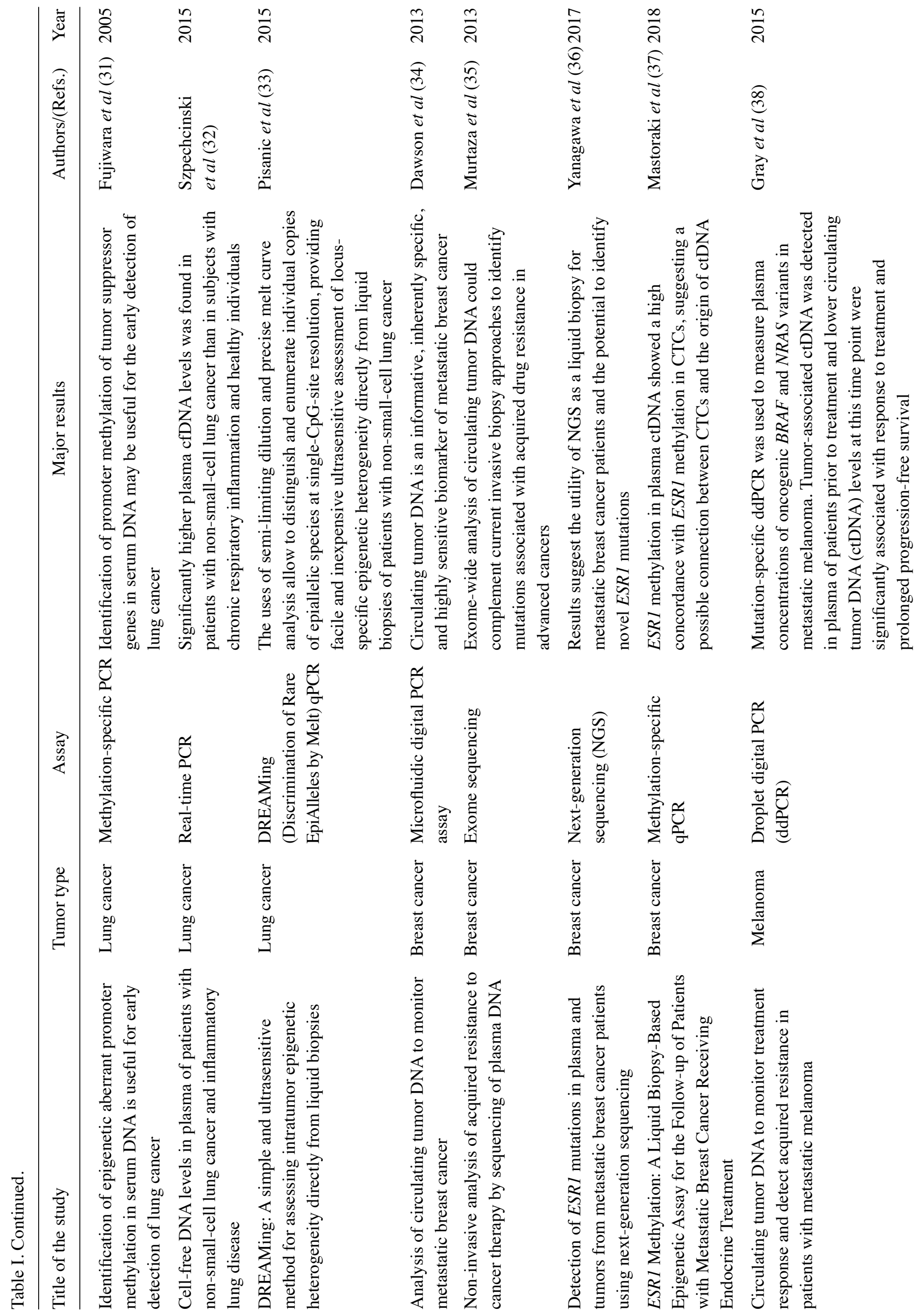




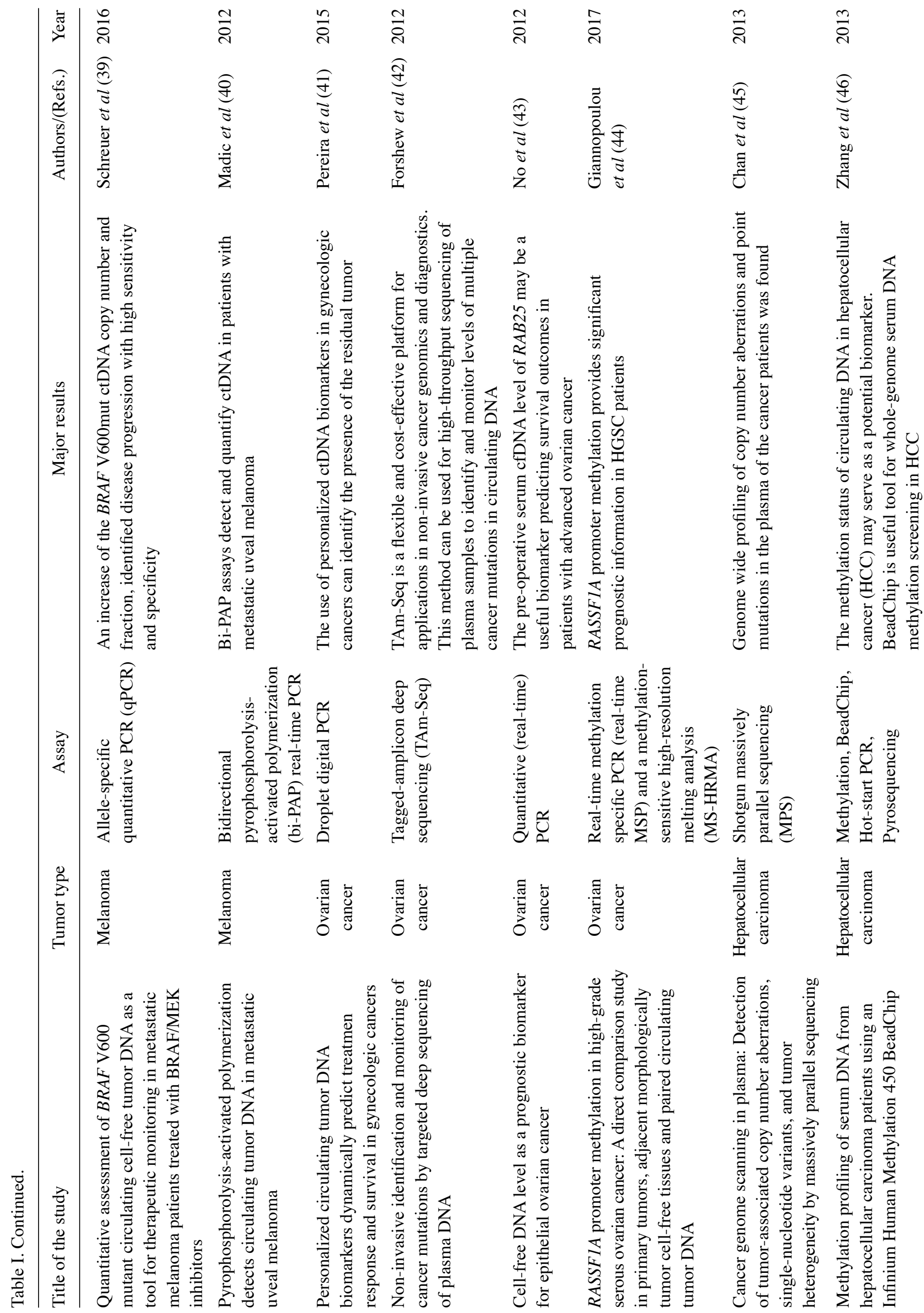




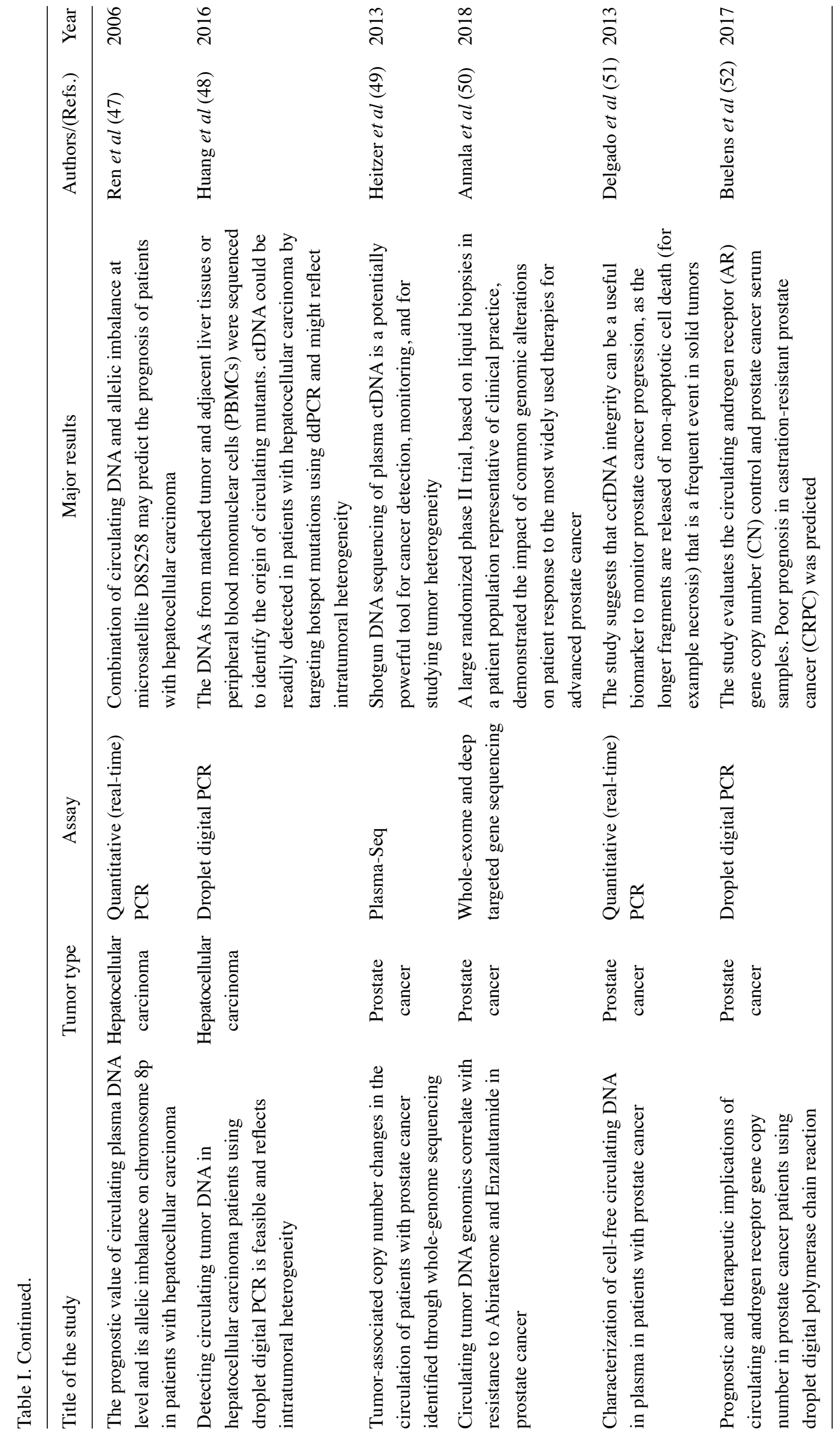




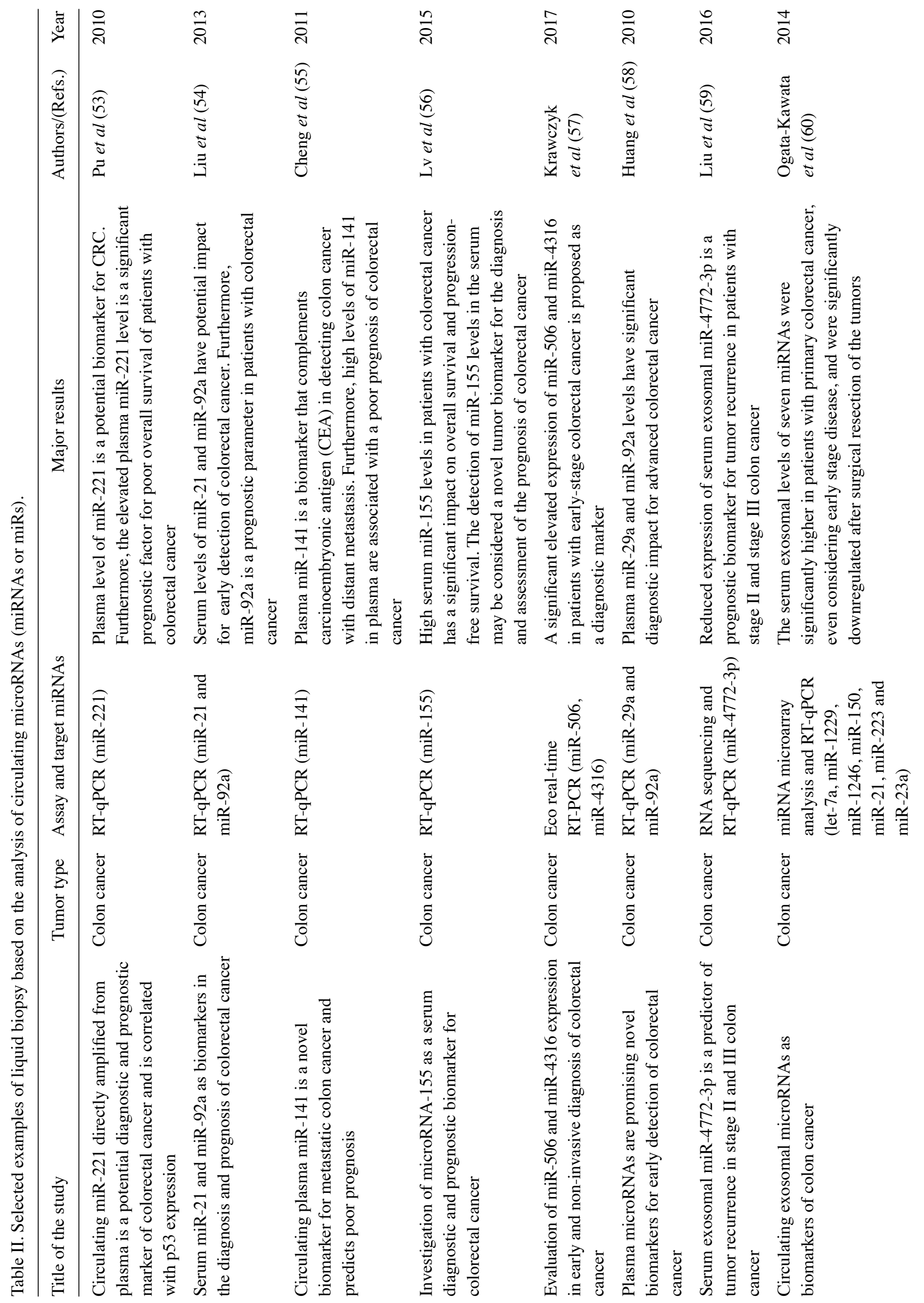




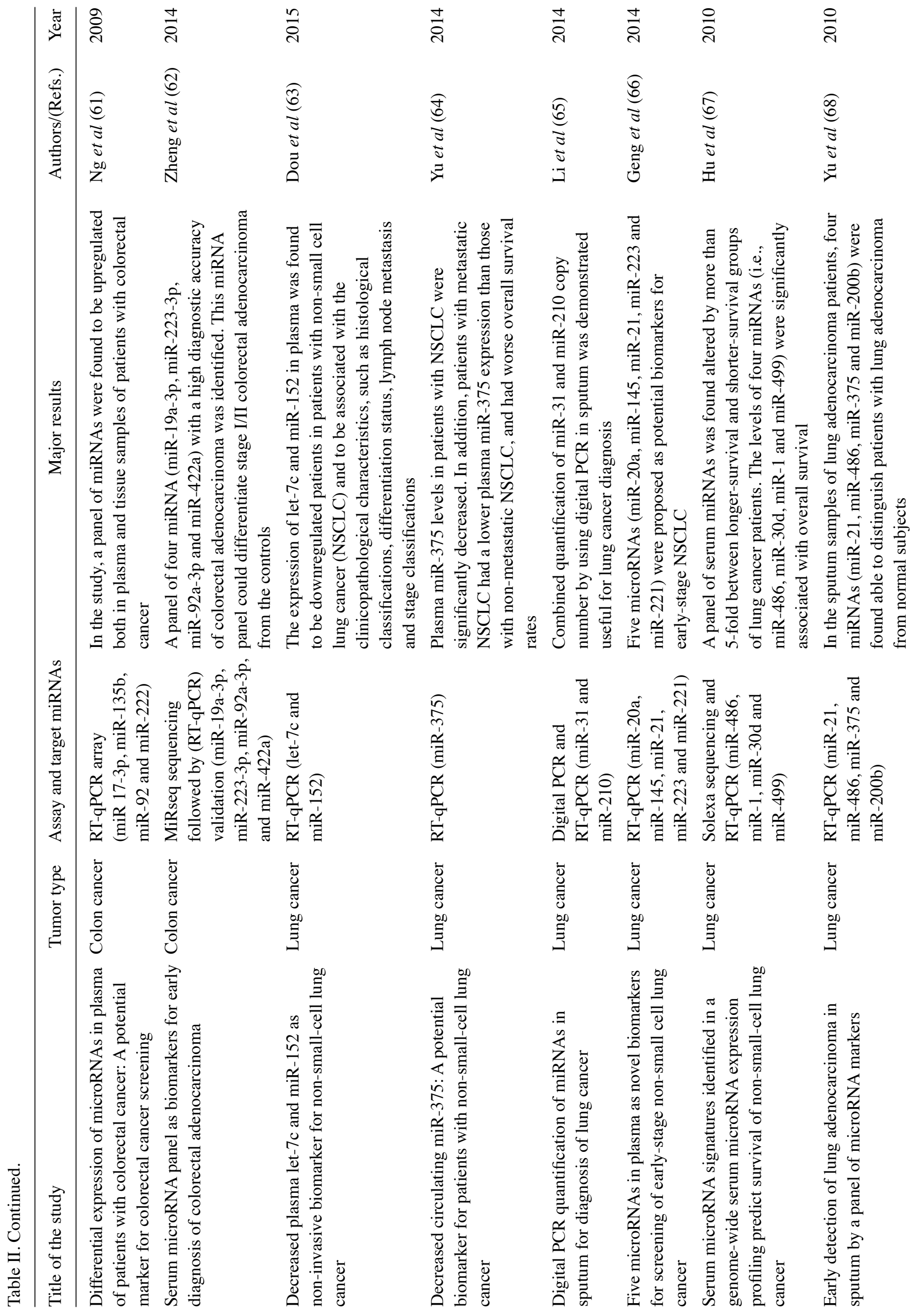




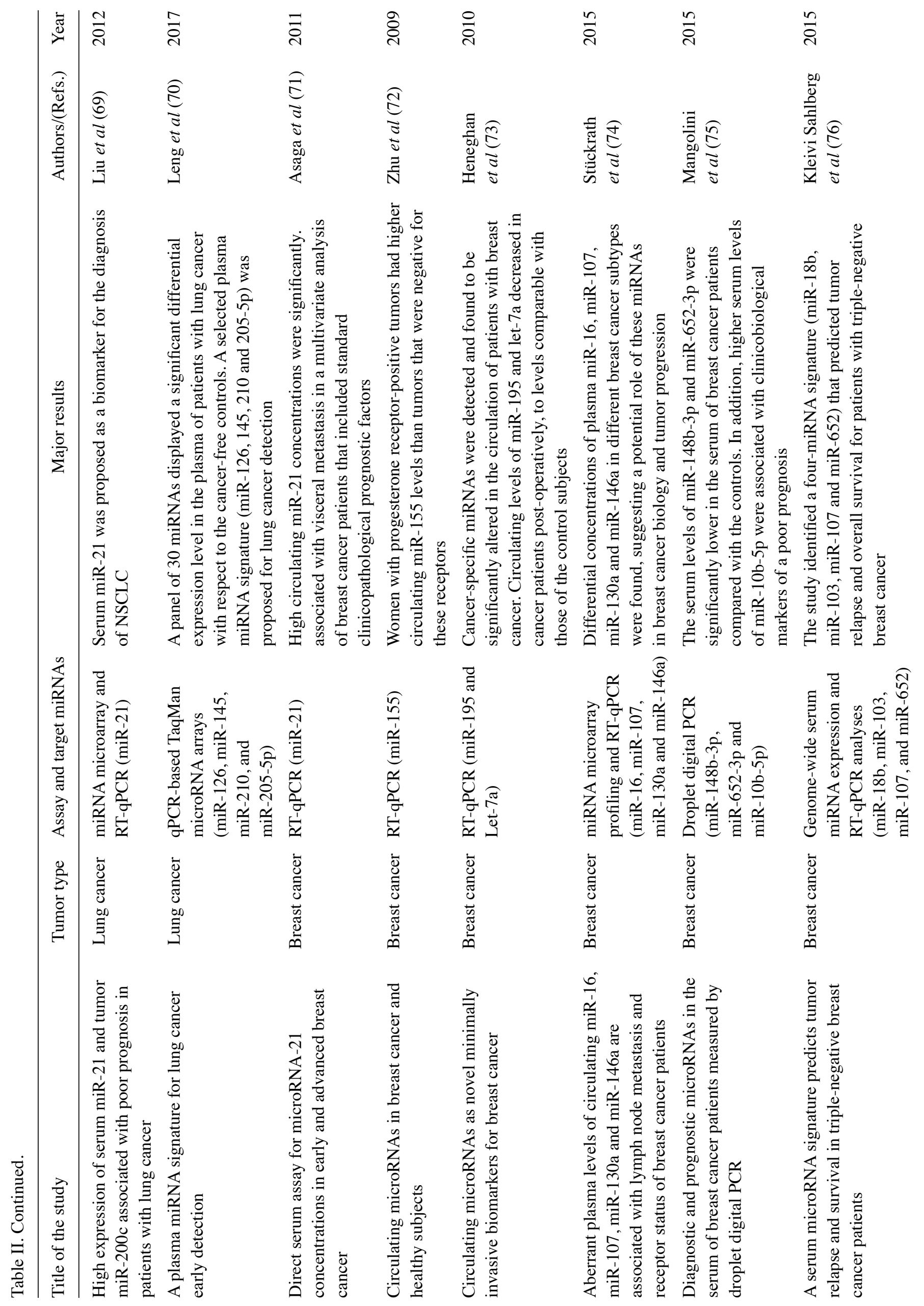




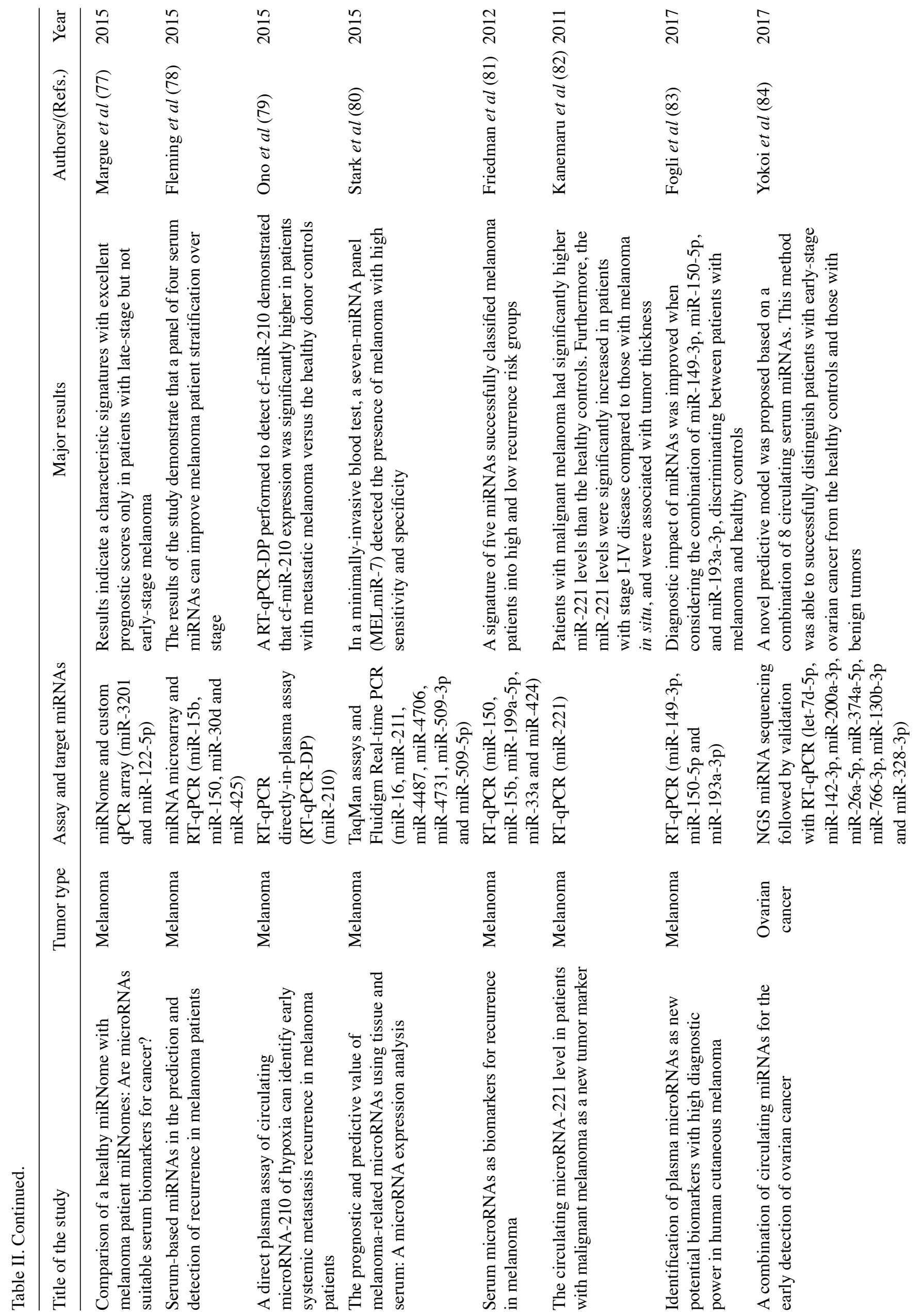




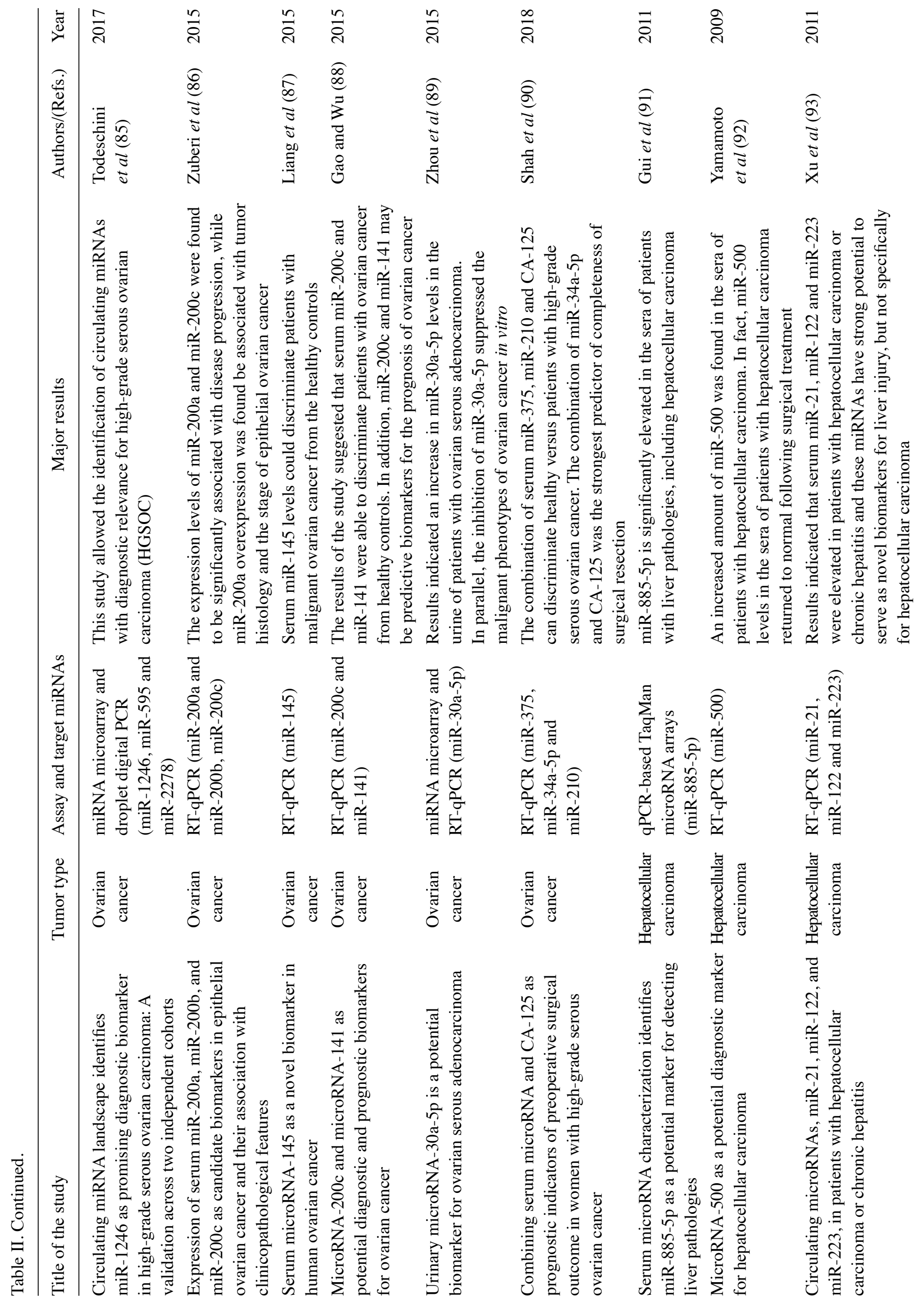




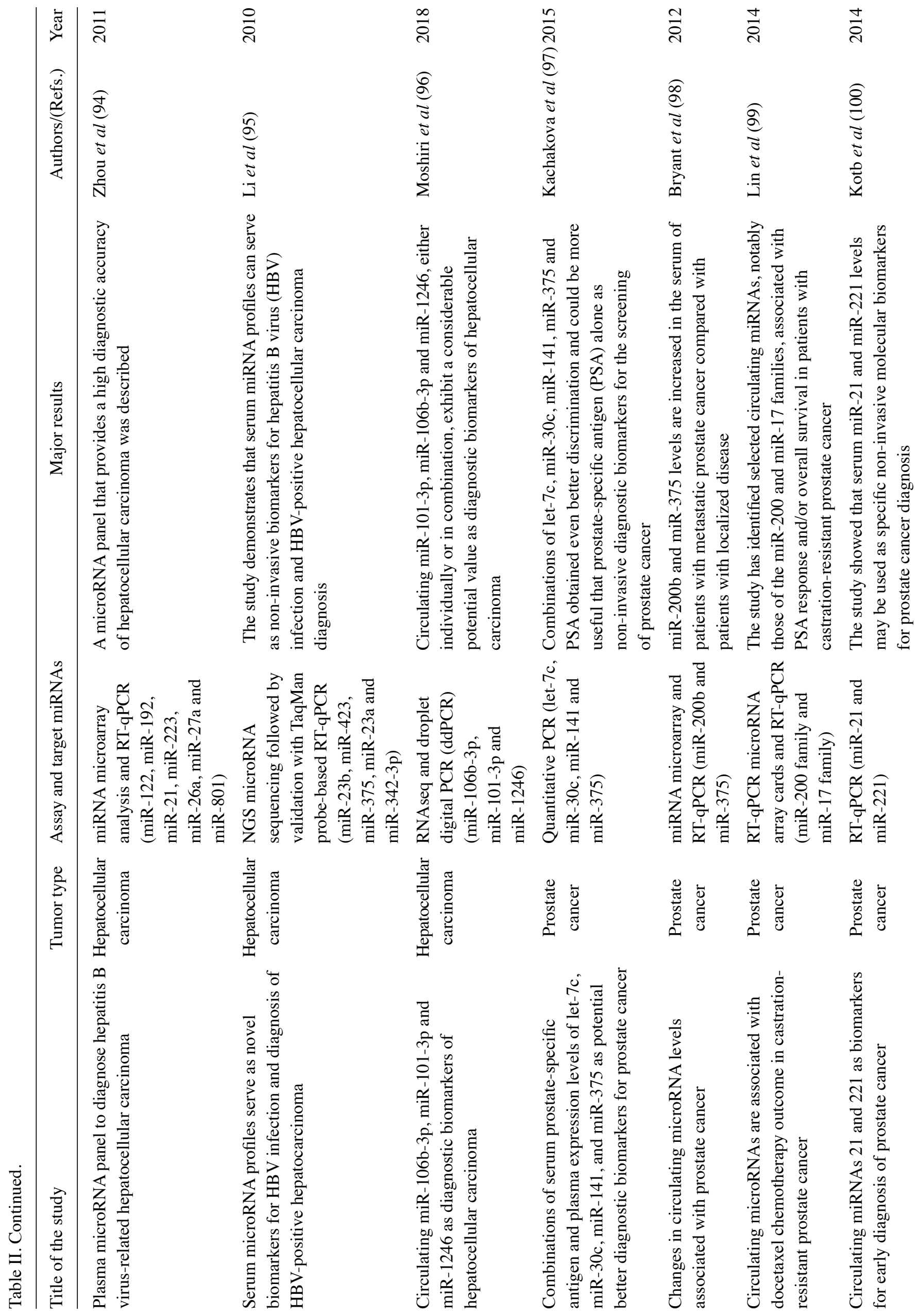




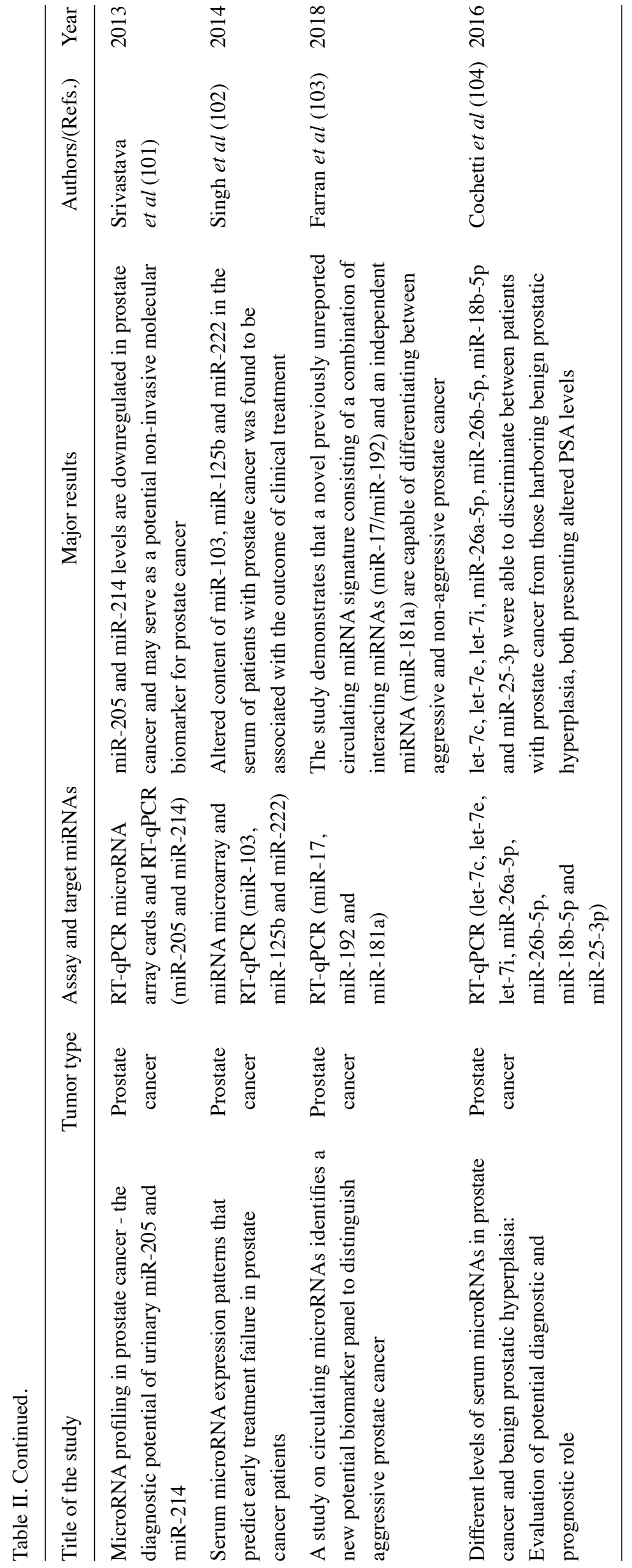


mainly mutations. The topic is extensive, and is the subject of a number of excellent reviews. Therefore, in this review, we focus on very specific examples, particularly in early-stage tumors. KRAS mutations are a case in point, since they serve as an actionable marker for EGFR blockade therapy, are highly prevalent, and have been thoroughly investigated. For instance, Brychta et al compared plasma and paired tumor samples from early-stage pancreatic cancer patients (105) by chip-based digital PCR. Their major aim was to identify selected KRAS codon 12 mutations (G12D, G12V and G12C) in circulating tumor DNA (ctDNA). Remarkably, circulating KRAS mutations were demonstrated in $72 \%$ of the patients, were associated with tumor burden, and were undetectable in the healthy controls. This study supports the use of liquid biopsy for early cancer diagnosis. Other studies focusing on $K R A S$ mutations in ctDNA were reported by Kinusaga et al (pancreatic cancer) (106), Couraud et al (lung cancer) (107), Perez-Carbonell et al (CRC) (108) and Case et al (lymphoblastic leukemia) (109). Table I summarizes the applicative examples of liquid biopsy for the identification of oncogene mutations, including the detection of EGFR mutations in the blood of lung cancer patients, now approved by regulatory bodies. These assays are of outmost interest and exemplify the profound difference between non-invasive liquid biopsy and invasive tumor tissue biopsy. Tissue biopsy may not reflect the genomic profile of the tumor in its entirety due to intra-tumor heterogeneity, multiple foci poorly accessible to sampling, and/or changes occurring during tumor development and/or therapy. On the contrary, the non-invasive liquid biopsy of plasma, urine or saliva samples may more effectively recapitulate the mutational complexity of the many populations (cryptic and clinically evident) accounting for tumor burden in a given patient. This makes liquid biopsy particularly suitable to identify truncal aberrations that, when targeted, may result in a considerably greater systemic clinical benefit, as compared to targeting site-specific aberrations (Lin et al, 2015) (110).

Molecular targets: Gene methylation. A variation on the theme is to look at non-mutational events marking the cancer genome. Particularly relevant in this context is DNA methylation. It has been known for quite some time that tumor progression is associated with the abnormal methylation of cancer genes. Both hypomethylation and hypermethylation have been reported. Most often, the specific DNA hypermethylation of tumor suppressor genes is observed in the context of widespread DNA hypomethylation. Since aberrant DNA methylation at specific promoter regions is a defined molecular feature of cancer, ctDNA methylation has been developed into a very promising molecular marker. DNA methylation is to date one of the preferred consensus circulating biomarkers in pre-symptomatic and symptomatic patients with CRC. This has been discussed by Warton et al (111) and by Mitchell et al (112), who have considered methylation-specific PCR assays as a novel approach for the assessment of low levels of DNA methylation in 29 regions of 17 genes. Eight differentially-methylated regions (DMRs) residing in the $B C A T 1$, GRASP, IKZFI and IRF4 genes, exhibited low positivity in the plasma of healthy subjects and high positivity $(>59 \%)$ in ctDNA from colonoscopy-confirmed patients with CRC.
Molecular targets: Circulating microRNAs. MicroRNAs (miRNAs or miRs) are a family of small (19 to 25 nucleotides in length) non-coding RNAs which play important roles in controlling post-transcriptional gene expression. Regulatory miRNAs reduce protein synthesis through selective interactions with complementary sequences of target messenger RNAs (mRNAs) $(113,114)$. Single or multiple mRNAs can be targeted at their 3'untranslated region (UTR), coding sequence (CDS), 5'UTR sequences, and it is calculated that $>60 \%$ of human mRNAs are miRNA targets (114). The miRNA/mRNA interaction occurs at the level of RNA-induced silencing complex (RISC) and is associated with the repression of translation or mRNA degradation, depending on the levels of complementarity with nucleotide sequences on the target mRNAs (115-118). Since their discovery and first characterization, the number of human miRNAs identified and deposited in the miRBase databases (miRBase v.22, www.mirbase.org) has been steadily increasing and is now $>2,500(119,120)$. Research on miRNAs has confirmed the complexity of this expanding miRNA/RNA network (117-122).

Alterations in miRNA expression have been associated with different human diseases. The guided alteration of specific miRNAs may potentially lead to innovative therapeutic protocols $(123,124)$. miRNAs function both as tumor promoters (oncomiRNAs and metastamiRNAs) and tumor suppressors $(125,126)$, depending on their regulatory preference for oncoproteins with opposing influences on cancer cells. Based on this, it is unsurprising that circulating cell-free miRNAs have been actively investigated as liquid biopsy analytes. OncomiRNAs are abundant in several extracellular body fluids (127-132), where they are protected and stabilized by exosome-like structures and small intraluminal vesicles produced by a variety of cells (including cancer cells) (127). Hence, elevated levels of several miRNAs (including miR-221, miR-222, miR-141, miR-92a, miR-21, miR-155, miR-506 and miR4316, miR-4772 and miR-29a) are present in the blood from patients with CRC $(53-62,133,134)$ and may contribute to the diagnosis and prognosis of patients with CRC (134). Furthermore, miRNAs may aid in the monitoring of therapeutic approaches. For instance, Ogata-Kawata et al reported that serum exosomal miRNA levels (let-7a, miR-1229, miR-1246, miR-150, miR-21, miR-223 and miR-23a) were higher in patients with $\mathrm{CRC}$ than in the controls, that this abnormally high levels were already detectable at early disease stages, and that they were significantly downregulated following surgical resection (60).

\section{Technologies}

In order to identify specific DNA mutations and quantify miRNA levels in plasma and other body fluids of cancer patients, several types of technologies for DNA/RNA analysis have been proposed. For cfDNA analysis, the golden standards are possibly quantitative PCR (qPCR) and digital PCR; however, several additional technologies have been proposed (Table I), such as polymerase chain reactionsingle strand conformation polymorphism (PCR-SSCP) analysis (27), multiplex digital PCR (dPCR), allele-specific qPCR $(18,39)$, whole genome sequencing (WGS) (28), cancer personalized profiling deep sequencing (Capp-Seq) (30), 
methylation-specific PCR $(31,37,44)$, the Discrimination of Rare EpiAlleles by Melt qPCR (DREAMing) (33), bidirectional pyrophosphorolysis-activated polymerization (bi-PAP) real-time PCR (40) and tagged-amplicon deep sequencing (TAm-Seq) (42). For miRNA analysis, qPCR and reverse transcription (RT)-PCR (53-58), NGS RNA sequencing (63), miRNA microarray analysis (60) and digital PCR (65) are the most commonly used technologies (Table II).

A common step, and under many respects a complication of all the above-mentioned technologies, is the need to amplify the minute amounts of target analytes by an enzymatic reaction with DNA modifying enzymes, most often Taq polymerase and its derivatives. Biosensing platforms hold great promise for the simple and rapid detection of cfDNA and cfRNA (135), since they skip this time-consuming, analyte-dependent, PCR amplification step. Novel PCR-free biosensing approaches are able to detect $K R A S$ and $B R A F$ mutations in the serum of patients with lung cancer and melanoma (136).

Digital PCR (137) is based on the limiting dilution of DNA, and single molecule detection to identify and quantify the target mutated DNA in a given sample $(138,139)$. This experimental approach is very useful for the identification of rare variants and in non-invasive diagnosis on peripheral blood, since only a small concentration of template is required for the analysis. Next generation sequencing (NGS) is a high throughput DNA sequencing technology which allows for the analysis, in a single reaction, a large variety of different DNA aberrations across multigene panels $(140,141)$, although comprehensiveness may somewhat detract from sensitivity. Different commercial NGS platforms are available, such as Genome Analyzer and HiSeq 2000 (Illumina), HeliScope (Helicos BioSciences), SOLiD and Ion Torrent (Life Technologies), Roche/454 (Roche). In these instruments, templates, primers or polymerase enzymes are immobilized on a solid support or on microbeads before sequencing, allowing the process of millions of microreactions carried out in parallel on each spatially distinct template.

However, as already pointed out, several challenges are related to liquid biopsy, the most important of which is the amount of target molecules to be detected and quantified. As far as cfDNA detection is concerned, these target molecules are so diluted by normal DNA that existing sequencing methods, such as Sanger sequencing, were not considered sufficiently sensitive to detect tumor-associated DNA mutation. As shown in Table I, the most commonly used approach was based on mutation-specific PCR, a technology proven to exhibit sufficient specificity and sensitivity allowing for the detection of the weak tumor signal present in the patient's circulation. This technology may be associated with important drawbacks when the quantification of miRNAs is considered, suffering from biases in the template-to-product ratios of the amplified target sequences (141). In addition, differential RT efficiency on different miRNA targets may also introduce variability when miRNA patterning is considered. Once again, PCR-free detection strategies are of great interest $(142,143)$.

\section{Experimental model systems for technological validation}

Liquid biopsy is a complex strategy requiring pre-analytical steps, post-analytical optimization, and the careful selection of optimal analytes for specific biological queries. In vivo model systems may be very useful in addressing and isolating these numerous individual variables (that are both technical and biological), and validate complex multi-step approaches. It is surprising, in this respect, that only few reports are available focusing on the use of animal models. For example, Garcia-Olmo et al directly compared the tumor ctDNA concentration and the number of circulating cancer cells in rats with xenograft tumors during the spread of CRC (144). Of note, they found that high ctDNA levels preceded the presence of CTCs. Rago et al (145) developed an elegant and highly sensitive qPCR test to quantify ctDNA by targeting LINE-I in mouse xenografts, demonstrating that this experimental system enables the monitoring of systemic tumor burden and close examination of the therapeutic management on a variety of animal tumor models. These studies demonstrate the importance of ctDNA and how it intertwines with CTCs. In a more recent study, Thierry et al (146) evaluated the relative quantitative contributions of non-tumor, tumor and mutated ctDNA, as well as ctDNA integrity, in an animal model. In this case, they found differences between patients with CRC and nude mice xenografted with human colon cell lines, suggesting that further research is necessary to validate in vivo model systems based on mice xenografted with tumor cell lines.

As for miRNAs, different independent studies have firmly demonstrated that miRNAs released into the circulation by tumor xenografts are distinct from 'background' mouse miRNAs. This is a key point, since pre-existing miRNAs present in mouse body fluids may be a powerful confounding parameter, possibly altering conclusions and implications of any circulating miRNA signature. In this respect, the use of laboratory mouse strains has the advantage that it sets a 'background' mouse miRNA pattern that is stable and easily quantifiable. Mitchell et al demonstrated that several miRNAs originating from xenografted human prostate cancer cells are present in the circulation (one of the most interesting being miR-141), and are readily measured in plasma, allowing a clear distinction between tumor-xenografted mice and controls (147). Selth et al (148) performed global miRNA profiling and identified a set of miRNAs exhibiting significantly altered serum levels in transgenic mice bearing prostate adenocarcinoma tumors. Among the most interesting miRNAs, they focused their attention on miR-141 and miR-375. Waters et al observed a complex miRNA dysregulation in the circulation of athymic nude mice subcutaneously injected with MDA-MB-231 cells. Some miRNAs (such as miR-10b) were undetectable in the circulation, some others (miR-195 and miR-497) were significantly decreased, the miR-221 content was not altered, and a positive correlation was observed between miR-497 and miR-195. That study highlighted the distinct roles of miRNAs in the circulation and in disease dissemination and progression, all of which may be candidates as molecular targets for diagnosis, as well as for systemic therapy (149). More recently, Greystoke et al developed a robust protocol that allowed for the specific profiling of human tumor miRNAs in microliters of tail vein plasma (150). In a recent study, Gasparello et al presented the analysis of KRAS variants and the content of miR-141, miR-221 and miR-222 in mice xenografted with colon cancer cell lines (151). These results support the existence of multiple, finely tuned (non-housekeeping) control 

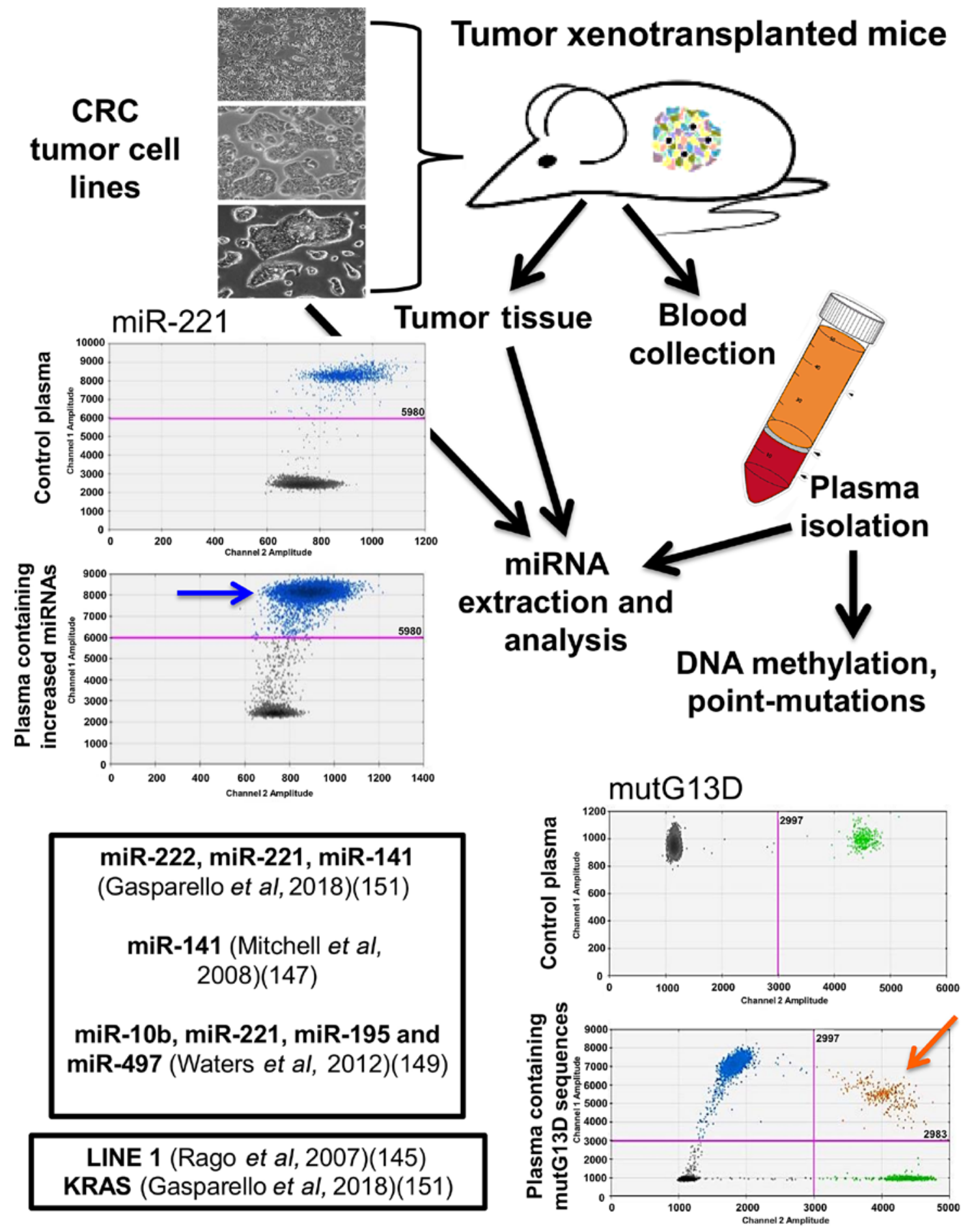

Figure 2. Study workflow on an in vivo model system to validate liquid biopsy protocols. Three human colorectal cancer cell lines can be selected as proxies of clinical cancers and cultured in vitro (top left panel) or used to establish tumor xenografts (top right panel). DNA and RNA can be isolated from cells, supernatants and tumor xenografts. Circulating tumor DNA (ctDNA) and microRNAs (miRNAs) can be isolated from blood plasma and droplet digital PCR (ddPCR), reverse transcription (RT)-ddPCR and RT-quantitative PCR (qPCR) can be performed to detect KRAS mutations and miRNA analysis. Examples of published studies are reported within the boxes. Blue and orange arrows indicate positive events associated with miR-221 and mutG13D content.

gateways that selectively regulate the release/accumulation of distinct ctDNA and miRNA species in culture and tumor xenograft models (Fig. 2).

\section{Specific biomedical applications}

ctDNA and miRNAs find application in a variety of clinical cancer settings.
Early diagnosis. Liquid biopsy for early lung cancer detection has been reviewed by Hofman (152) and by Pérez-Ramírez et al (153). Coupled with thoracic imaging, liquid biopsy is a powerful diagnostic tool, and potentially provides surveillance recommendations for high-risk populations without a detectable nodule. In a study on patients with CRC, Bedin et al (154) examined a large cohort of patients with CRC in comparison to healthy subjects and patients with adenomatous lesions. In 
their study, the presence and integrity of plasma cfDNA and the methylation profile of two gene promoters were evaluated. The cfDNA concentration and cfDNA integrity were found to be increased in patients with $\mathrm{CRC}$, and were associated with a poor prognosis. A lower extent of DNA methylation was observed in cfDNA as compared to tissue DNA.

With respect to alterations affecting cancer drivers, a high prevalence was previously described by Allenson et al of mutant $K R A S$ in circulating exosome-derived DNA from patients with early-stage pancreatic cancer (155). One very interesting observation of their study was that exosomes from viable cancer cells may reflect a different biology than cfDNA shed from dying tissues, including normal tissues. The information that the analyzed ctDNA is derived from actively metabolizing cancer cells with invasive potential, and not from normal cells, is certainly a crucial issue for early diagnosis. In this respect, Allenson et al (155) observed that the size of ctDNA differs depending on whether it is released from necrotic and dying cells or from live cells. The former is contained in cfDNA, the latter is included in the exosome-DNA fraction. The conclusion of their study was that exosomes should be considered as distinct sources of tumor DNA that may be complementary to other liquid biopsy DNA sources. In addition, circulating mutant KRAS was found in a minority of healthy samples, suggesting that care should be exercised when proposing liquid biopsy as a broad cancer-screening method.

As far as miRNA-based early diagnosis, an interesting study by Shimomura et al employed a highly sensitive microarray assay for the evaluation of serum miRNA expression profiles (156). In this large study, a total of 1,280 serum samples from patients with breast cancer were tested. In addition, 2836 serum samples were obtained from non-cancer controls, 451 from patients with other types of cancers, and 63 from patients with non-breast benign diseases. The expression of miRNAs was compared between breast cancer and non-breast cancer patients. The conclusion was that a set of five miRNAs (miR-1246, miR-1307-3p, miR-4634, miR-6861-5p and miR$6875-5 \mathrm{p}$ ) discriminated breast cancer from healthy control and non-breast cancer patients.

Staging and prognosis. Schröck et al (157) presented a study on free-circulating methylated DNA for the diagnosis, staging and prognosis of head and neck squamous cell carcinoma patients. In their study, the DNA methylation of two genes [short stature homeobox 2 (SHOX2) and septin (SepT9)] was quantified in plasma before treatment, and thereafter longitudinally during follow-up. The methylation levels were associated with the tumor and nodal category, and increased DNA methylation levels were associated with a shorter survival. On the whole, the data independently obtained in different laboratories support the hypothesis that the testing of DNA methylation in plasma is a powerful diagnostic tool for staging, risk stratification and disease monitoring. Patients with initially high biomarker levels may benefit from intensified treatment and surveillance. The marker-driven, timely detection of recurrent/metastatic disease may guide successive lines of treatment, thereby improving patient outcomes.

Therapeutic outcome. One example demonstrating the possible role of liquid biopsy in predicting therapeutic outcome has been reported by Quandt et al (158) who discussed how information obtained from liquid biopsies may contribute to the clinical decision-making process for cancer immunotherapy. This issue is of great interest since the application of immune checkpoint blockade over the past decade has revolutionized the treatment of a number of malignancies, leading to significantly improved survival. In this context, liquid biopsies are proposed to monitor treatment efficacy, acquired resistance to therapy and assign prognosis. A second example was published by Goodall et al (159) on cfDNA to guide prostate cancer treatment with poly(ADP)-ribose polymerase (PARP) inhibition. They reported whole exome sequencing of serial cfDNA samples collected during the treatment of patients with prostate cancer with the PARP inhibitor, olaparib. Decreases in the cfDNA concentration were found to be associated with a favorable outcome. All tumor tissue somatic DNA repair mutations were detectable in cfDNA, and allelic frequencies of somatic mutations decreased selectively in responding patients. At disease progression, following response to olaparib, multiple sub-clonal aberrations and somatic mutations in DNA repair genes (BRCA2 and PALB2) emerged as mechanisms of resistance. These data support the role of liquid biopsies as predictive, prognostic, response and resistance biomarkers in prostate cancer.

Final considerations on the management of cancer patients, follow-up and treatment monitoring. The results obtained thus far have indicated that liquid biopsy considerably affects systemic cancer therapy in metastatic cancer, due to the relevant information it provides to the medical oncologist. This is expected to improve key clinical parameters, such as patients overall survival and quality of life. This should be considered a major advantage of liquid biopsy (as outlined in Fig. 3), since the tissue biopsy of metastatic foci, is not only invasive, but is limited to certain locations, does not reflect clonal heterogeneity and multiple biopsies (even assuming they are feasible) may not be easily accepted, and may ingenerate doubts and contradictory diagnostic reports. Along this line, a droplet digital PCR (ddPCR) study by He et al (160) on 120 patients with a diverse EGFR mutational status supported an association between liquid biopsy and outcome. Of note, it was found that the mutant signature was stable and marked dynamic changes during the treatment allowing efficient and continuous disease profiling, which is expected to greatly facilitate the clinical decision-making process.

\section{PCR-free detection strategies}

Despite the fact that the majority of the analytical technologies are based on PCR and RT-PCR (see the Technologies section above and Tables I and II), PCR-free methods have attracted great interest in biomedicine. In fact, several articles have been published dealing with PCR-free methods for the detection of point mutations. In addition to the already cited limitation of PCR-based approaches, the need for repeated steps involving heating and cooling is an important limitation of all the PCR-based technologies, particularly when the PCR steps for the amplification of nucleic acids are associated with procedures performed in microfluidic-based devices (143,161-164). Several alternative isothermal-amplification methods (which 

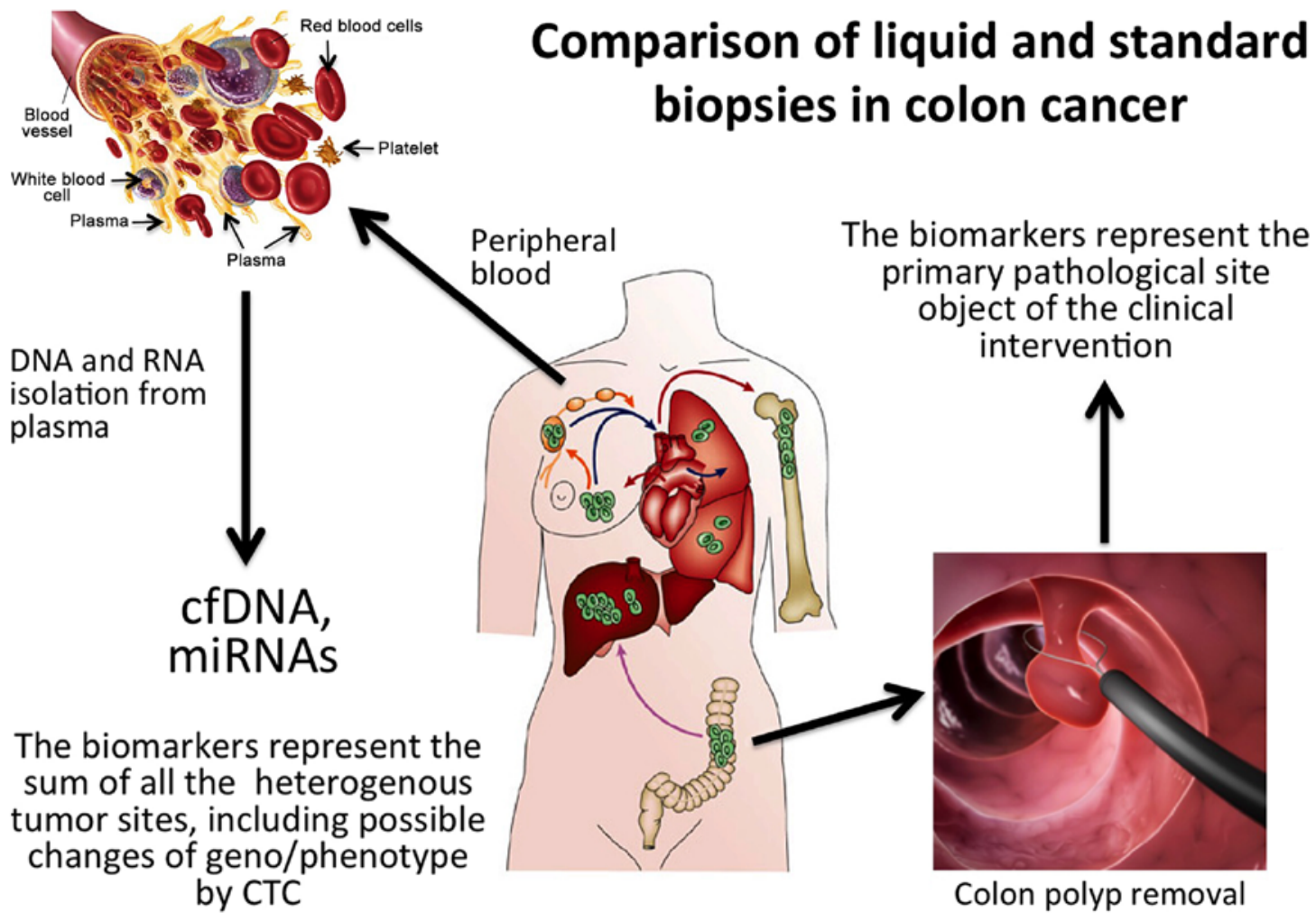

Figure 3. Comparison of liquid and standard conventional tissue biopsies in colorectal cancer (CRC). Tissue biopsy samples single disease sites whereas liquid biopsy potentially samples all tumor sites, including circulating tumor cells.

do not require thermal cycling) have been developed to overcome this limitation, including nucleic-acid-sequence-based polymerization (NASBA), loop-mediated amplification (LAMP), helicase-dependent amplification (HAD), rolling-circle amplification (RCA), recombinase-polymerase amplification (RPA) and multiple-displacement amplification (MDA) (142). Recently, isothermal circular-strand-displacement polymerization (ICSPD) has emerged as a novel and promising method for nucleic-acid amplification and detection (163). Finally, promising opportunities are offered by selected isothermal amplification approaches that are based on a simple design of the amplification process and can be integrated in microfluidic devices (142). Such methods allow for the minimization of potential sample contaminations and minimize the sample volume required for the analysis (143). In this respect, the direct detection of point mutations in non-PCR-amplified human genomic DNA has been recently demonstrated by surface plasmon resonance imaging (SPR-I). Attomolar concentrations of target genomic DNA have been detected, demonstrating the ultra-sensitivity of the new method and its potential application in several biomedical fields, including liquid biopsy methods (164).

\section{Patents and clinical trials on liquid biopsy and ultrasensitive detection systems}

Tables III (165-173) and IV (174-182) summarize patents and patent applications related to the development of liquid biopsy protocols in cancer diagnosis. It is of interest to go through the claims of these patents, as they reflect the consideration given to liquid biopsy by a large part of the scientific community.
Several patents build on the concept that mutations of tumorassociated genes (present in cfDNA from body fluids) and/or miRNA profiles are prognostic (associated with outcome), and/ or predictive (associated with susceptibility to specific treatments). Examples of patents related to cfDNA and miRNAs are numerous and have steadily increased over the years. In fact, CTC counts, and molecular signatures originating from or associated with CTCs have been shown to be associated with conventional cancer molecular genotyping in tissues.

For instance, in EP2426217A1 (166) a method is described for detecting cell free nucleic acids, preferably cfDNA in a body fluid sample from an individual or a patient. A general claim, present in many other similar patent applications, relates to a method that comprises the step of accurately and sensitively determining the concentration of cell free nucleic acids in the sample and/or the index of integrity of said cell free nucleic acid and/or the determination of the presence of genetic polymorphisms [such as known single nucleotide polymorphisms (SNPs) or mutations]. The invention encompasses also a method to discriminate body fluid individuals where cfDNA are highly released. The majority of the approaches described in Table III have been validated on a variety of body fluids (urine, saliva, serum, plasma, bone marrow, lymphatic fluid, lacrimal fluid, serous fluid, peritoneal fluid, pleural fluid, ductal fluid from breast, gastric juice, or pancreatic juice) and cancers [breast cancer, CRC, periampullary cancer, melanoma, prostate cancer, gastric cancer, leukemia/lymphoma, renal cell carcinoma, hepatocellular carcinoma (HCC), neural-derived tumor, head and neck cancer, lung cancer, or sarcoma]. In addition to SNPs and tumor-associated mutations (presented in EP2426217A1, US7718364B2, WO2016168844A1 and 


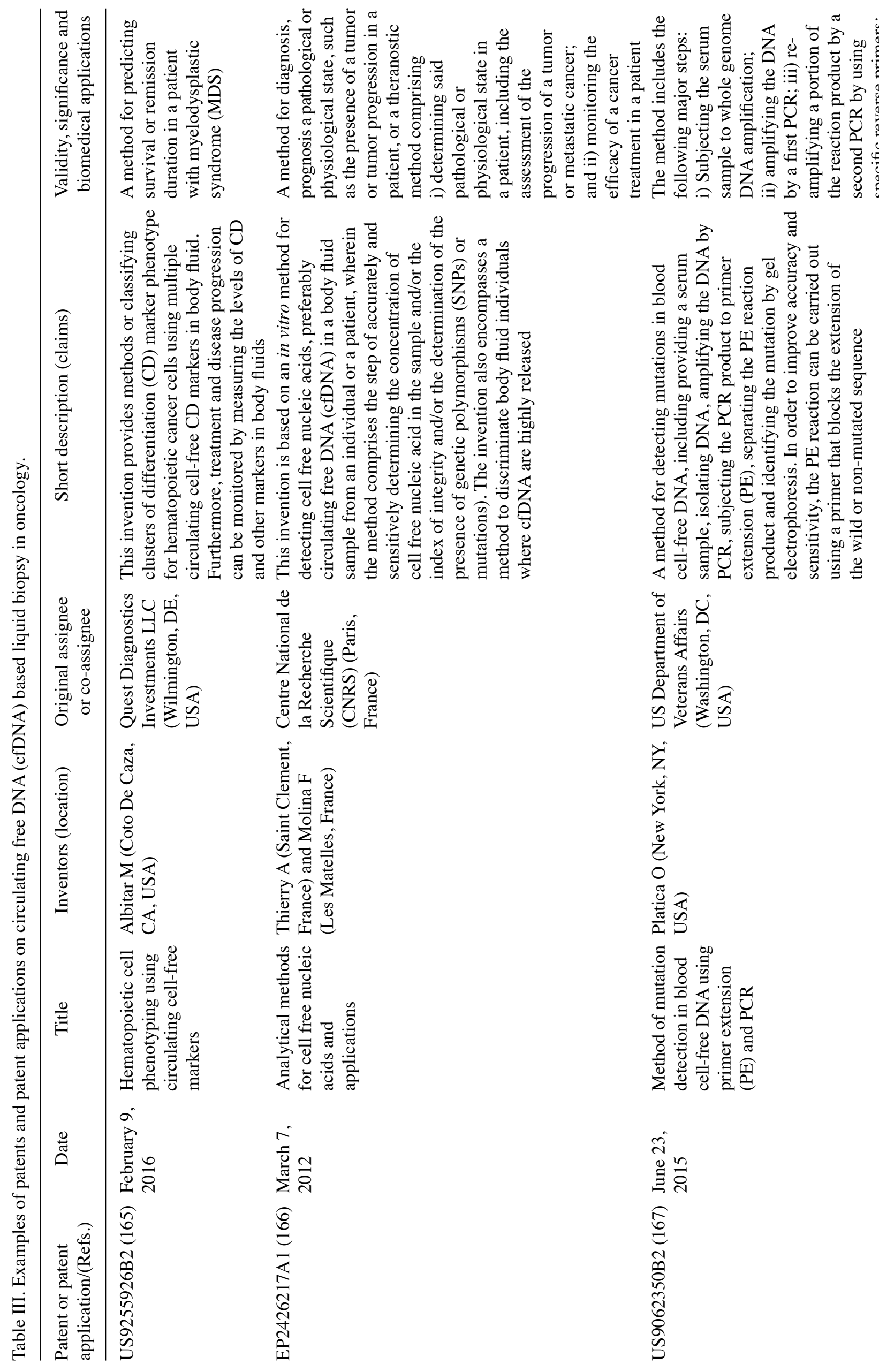




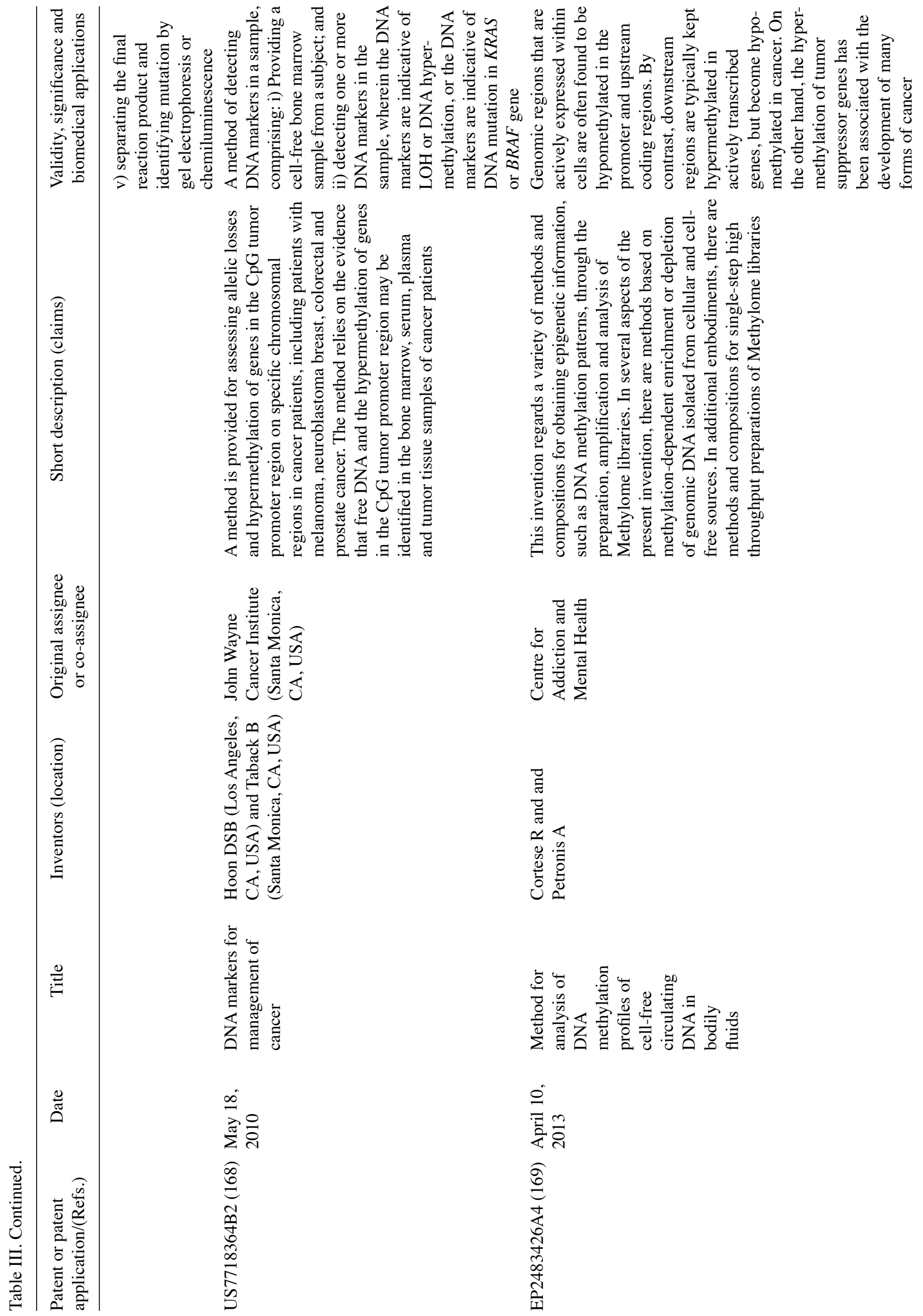




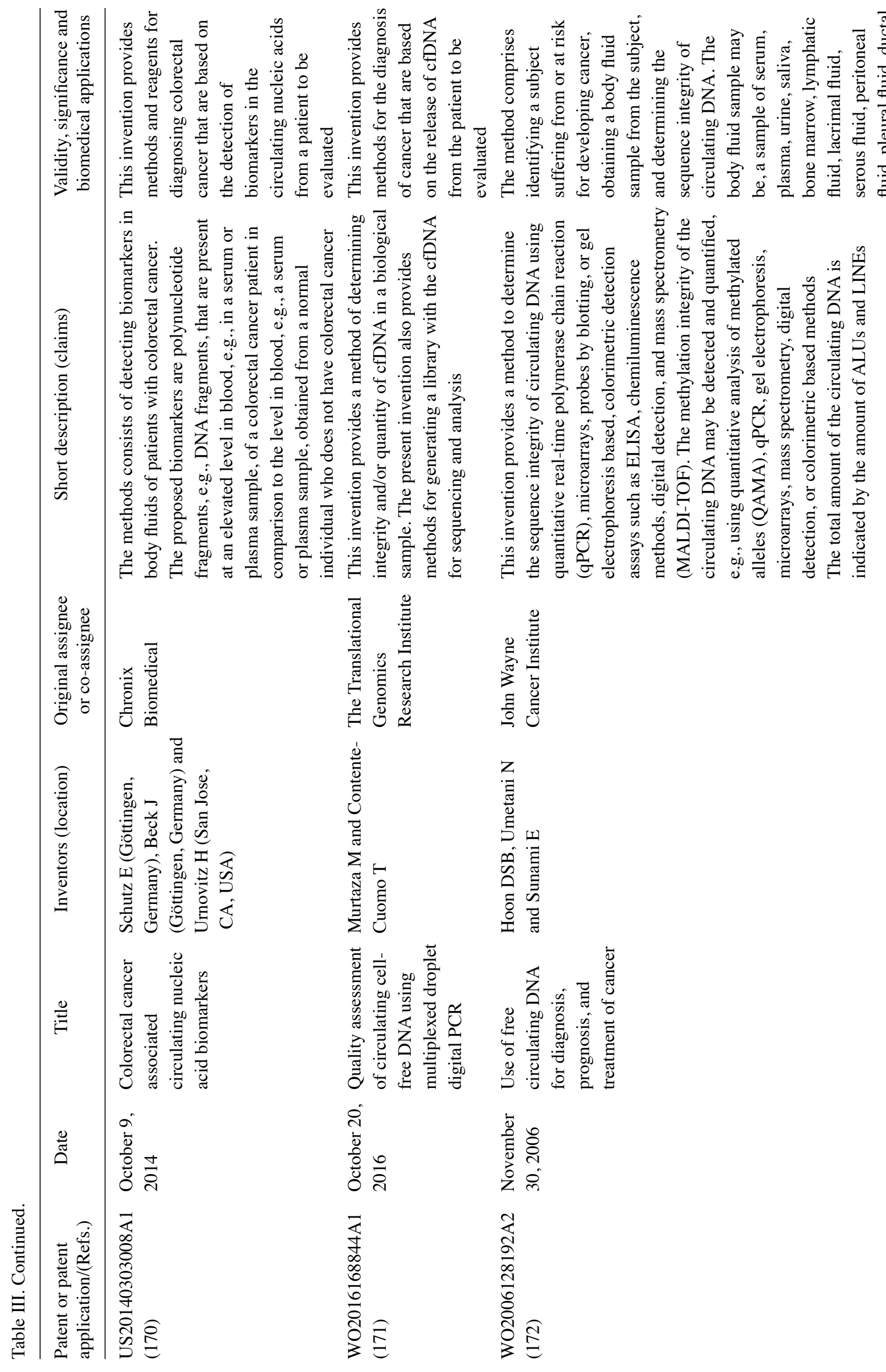




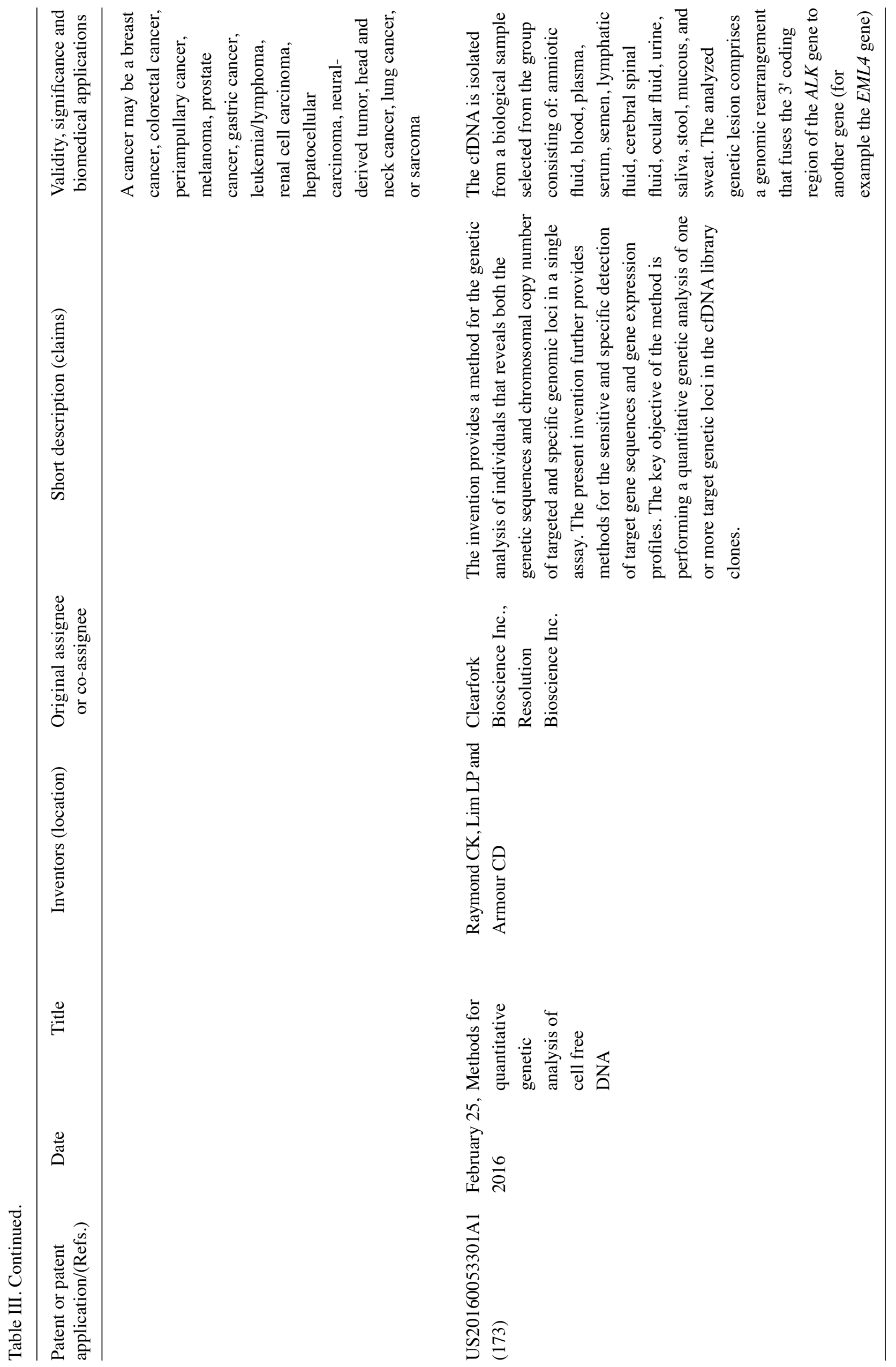




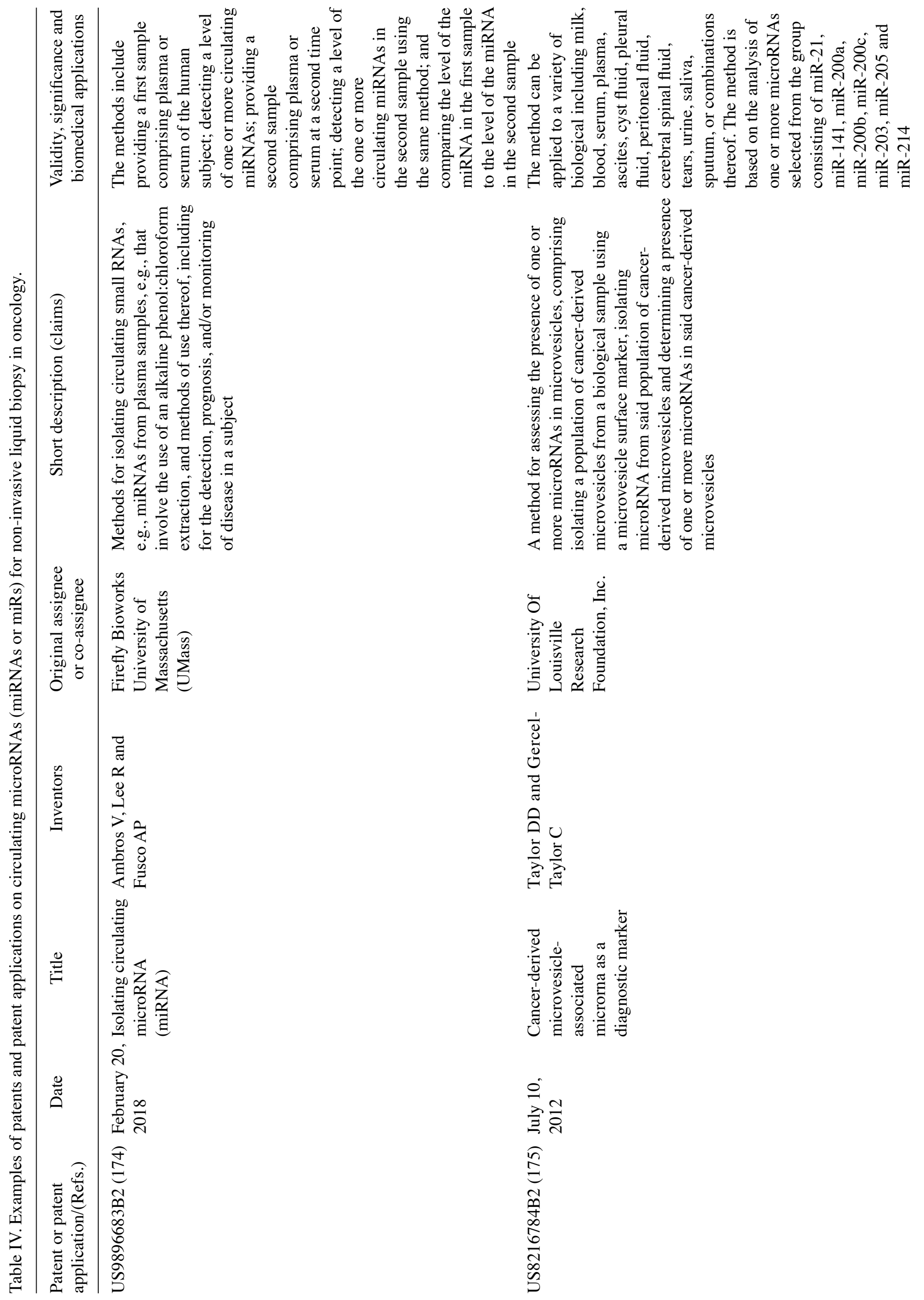




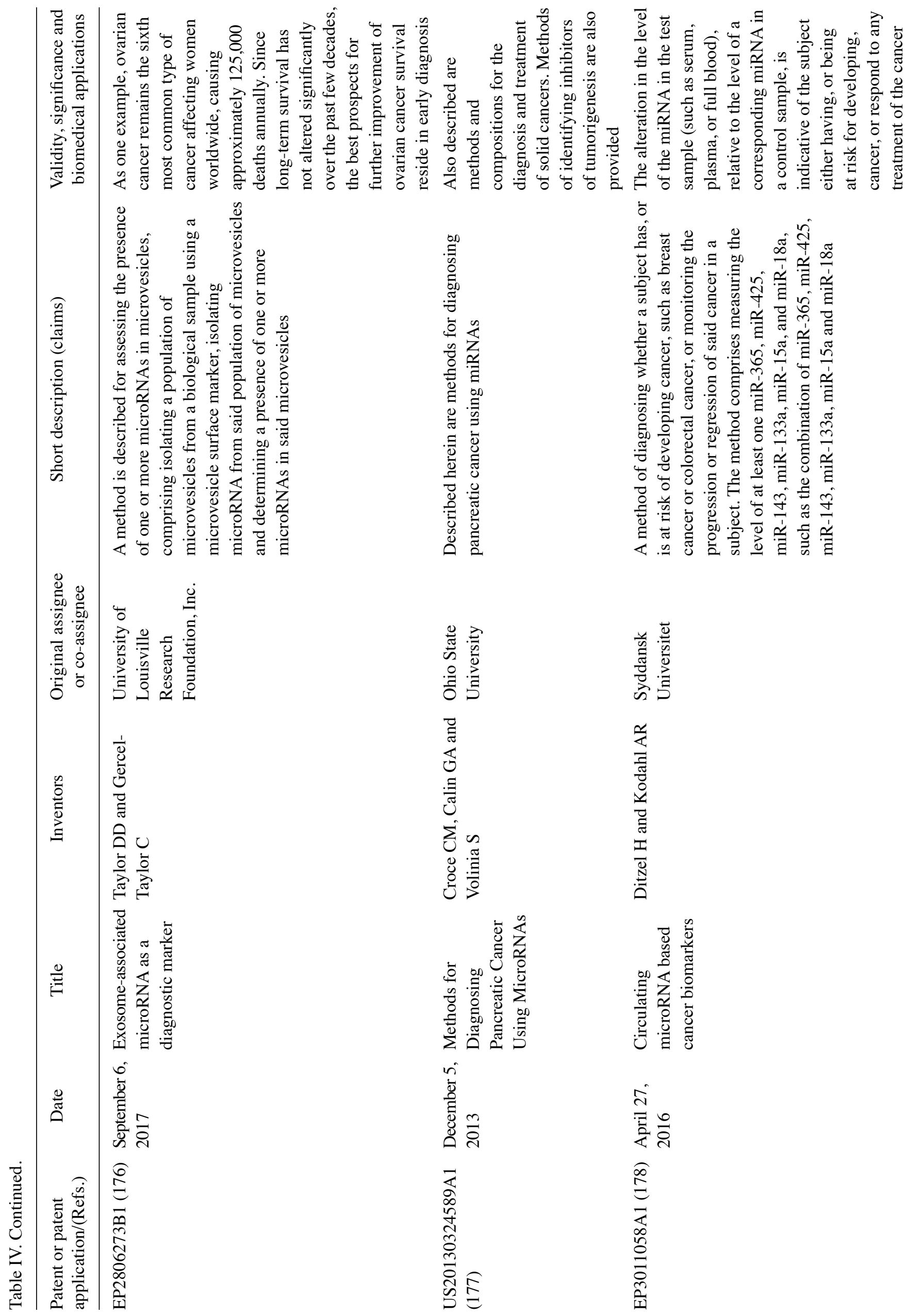




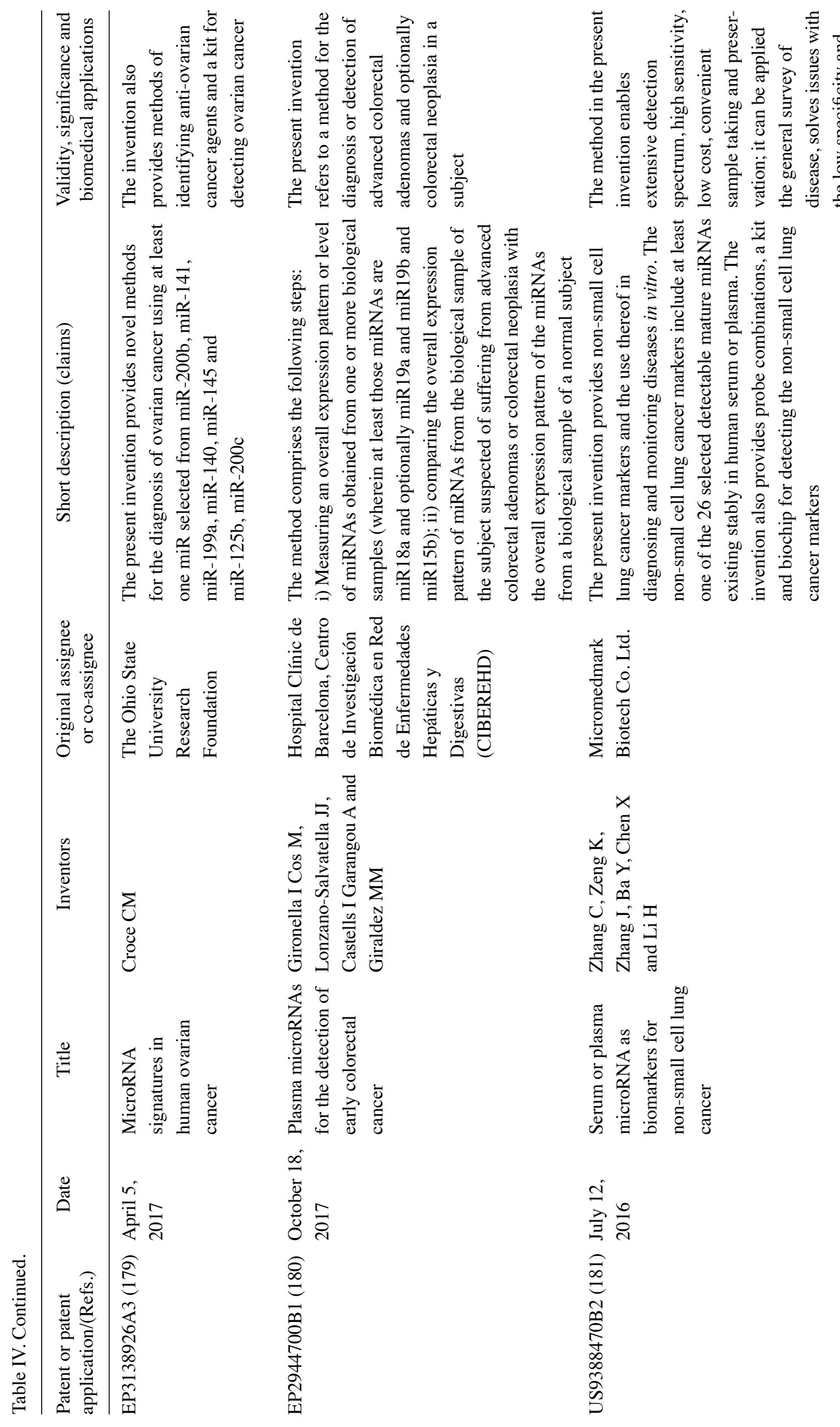


US20160053301A1) $(166,168,171,173)$, another interesting marker is DNA methylation. In US7718364B2 (168), a method is provided for assessing allelic losses and the hypermethylation of genes in the $\mathrm{CpG}$ tumor promoter region on specific chromosomal regions in patients suffering from melanoma, neuroblastoma, breast, colorectal and prostate cancer. The method is based on the evidence that free DNA and hypermethylation of genes in the $\mathrm{CpG}$ tumor promoter region may be identified in the bone marrow, serum, plasma and tumor tissue samples of cancer patients. Table III lists examples of patents and patent applications focusing on cfDNA analysis in the body fluids of cancer patients.

As far as miRNAs are concerned, US8216784B2 (175) and EP2806273B1 (176) deal with cancer-derived microvesicleassociated miRNAs as a diagnostic marker for the detection of cancer. The method is based on the analysis of one or more miRNAs selected from a group comprising miR-21, miR-141, miR-200a, miR-200b, miR-200c, miR-203, miR-205 and miR-214. The method can be applied to a variety of biologicals, including milk, blood, serum, plasma, ascites, cyst fluid, pleural fluid, peritoneal fluid, cerebral spinal fluid, tears, urine, saliva, sputum, or combinations thereof. EP3011058A1 (178) is an example of patents focusing on total miRNA analysis. In addition, in this case, a shortlist of candidate miRNAs is provided, such as the combination of miR-365, miR-425, miR-143, miR-133a, miR-15a and miR-18a. The alteration in the level of the miRNA in the test sample (such as serum, plasma, or whole blood), relative to the level of a corresponding miRNA in a control sample, is indicative of the subject either having, or being at risk of developing, cancer, or the response of a subject to any treatment for the cancer. Further examples of miRNAs identified as cancer biomarkers are shown in Table IV.

Liquid biopsy is implemented (and is technologically tested) in several ongoing clinical trials (Tables V and VI) (183-204). For instance, NCT02639832 (183) is focused on the presence of tumor-derived CTCs or ctDNA using an investigational medical device known as the LiquidBiopsy. Using the LiquidBiopsy platform, recovered cells or DNA can also be investigated to obtain genetic information that may be useful to physicians for treating and understanding disease. The LiquidBiopsy device is able to purify the tiny numbers of tumor cells or ctDNA in blood. Even if a tumor is too small to be found by other means, such as an X-ray, it is possible that ctDNA or CTCs may be found in the blood. Genetic information can then be recovered from these cells or DNA to identify genetic alterations that are related to abnormal growth in a tumor. The proponents claim that this will potentially allow researchers to study tumor cells or tumor DNA from a blood sample instead of a biopsy sample, and may influence cancer diagnosis, treatment and drug selection in the future. In NCT02784639 (195) a method is employed which simultaneously allows the determination of three parameters: The specific quantification of tumor-derived ccfDNA, the ccfDNA fragmentation index and SNP or point mutation detection. The evaluation and validation of the method will be performed by determining the KRAS/BRAF mutational status prior to anti-EGFR therapy in patients with CRC. The protocol will detect the six most frequent KRAS mutations in CRC (G12D, G12V, G13D, G12S, G12C and G12A) and BRAF V600E. The goal of this multicenter prospective study is to validate, and ultimately translate in 


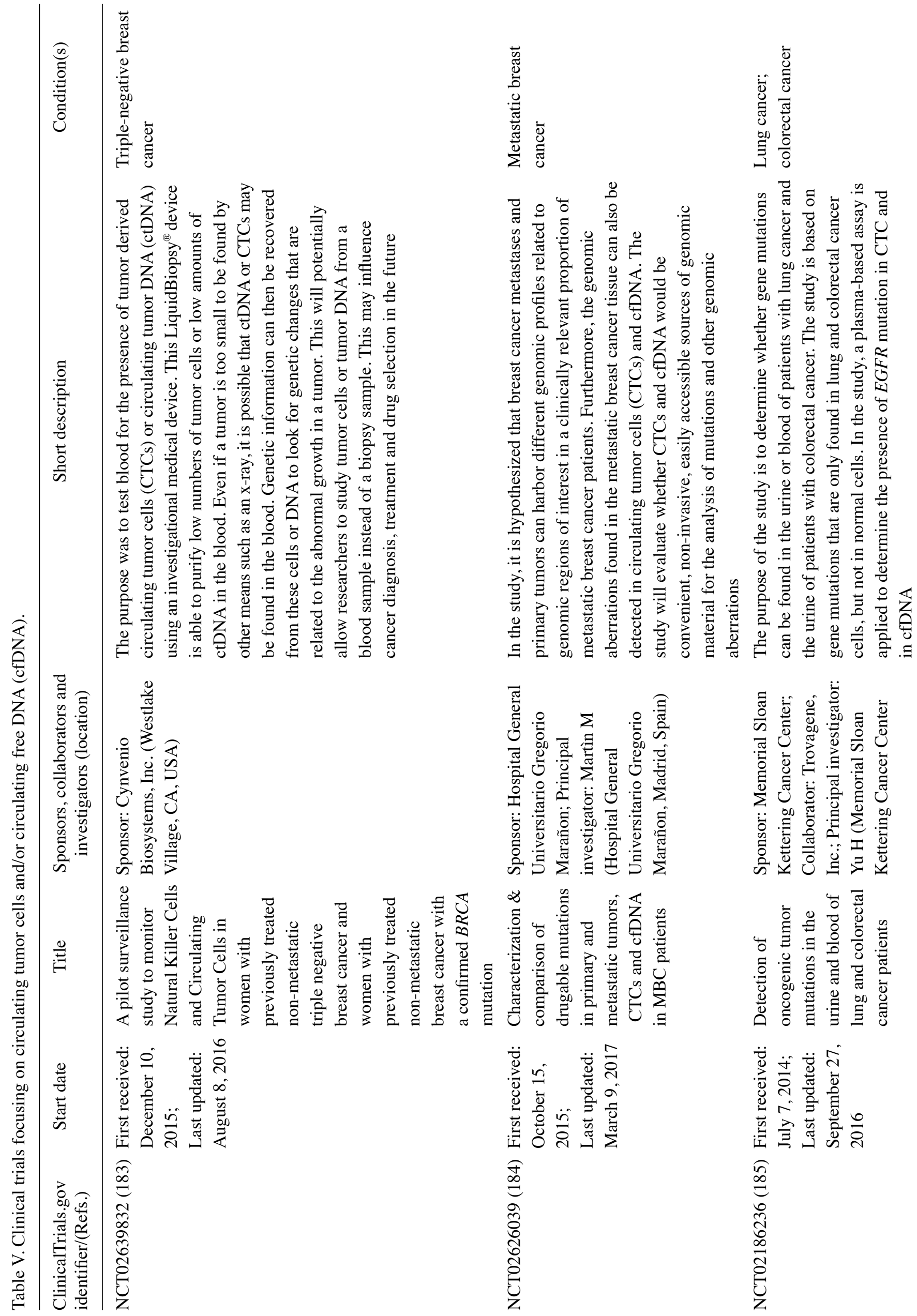




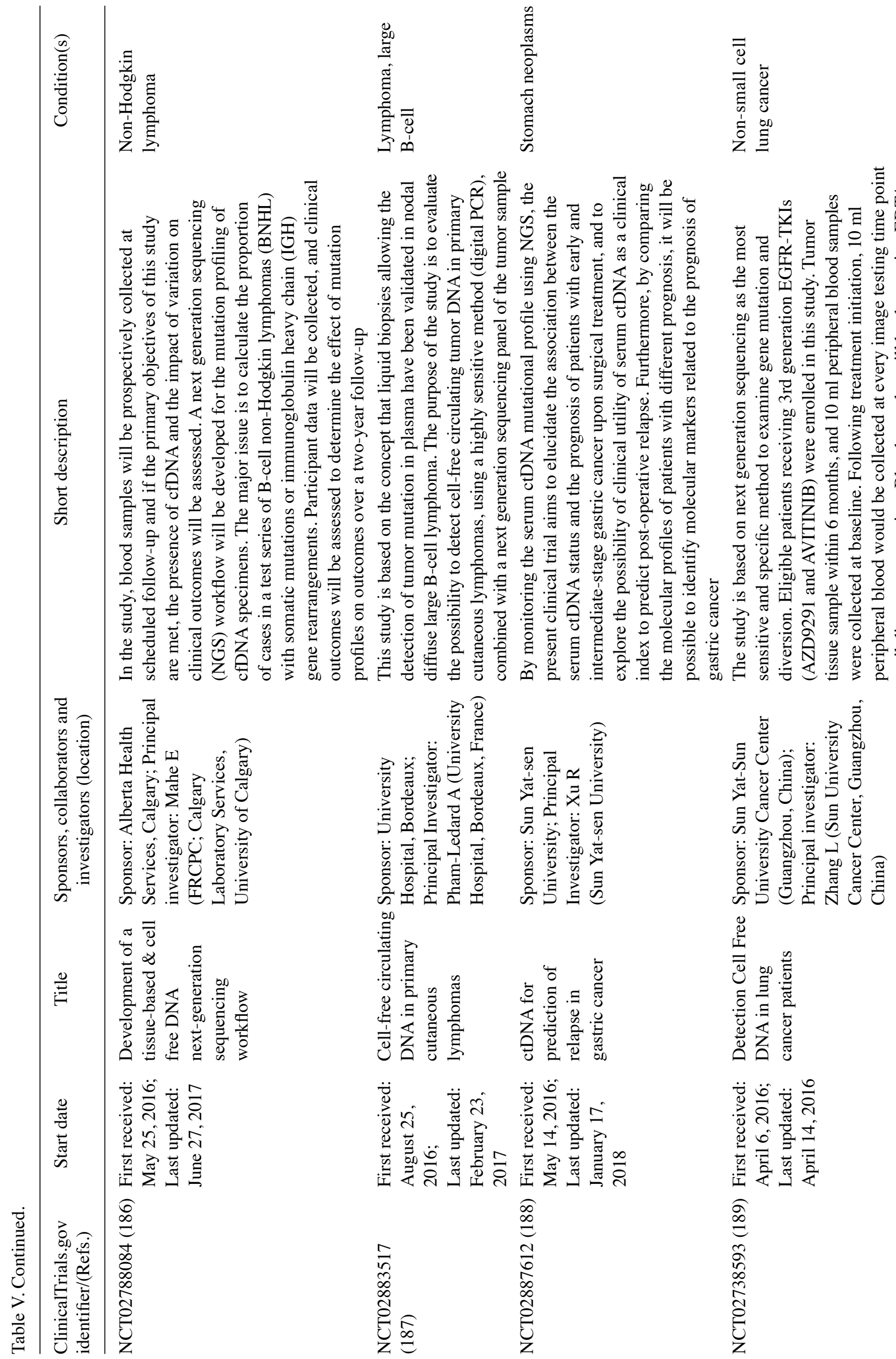




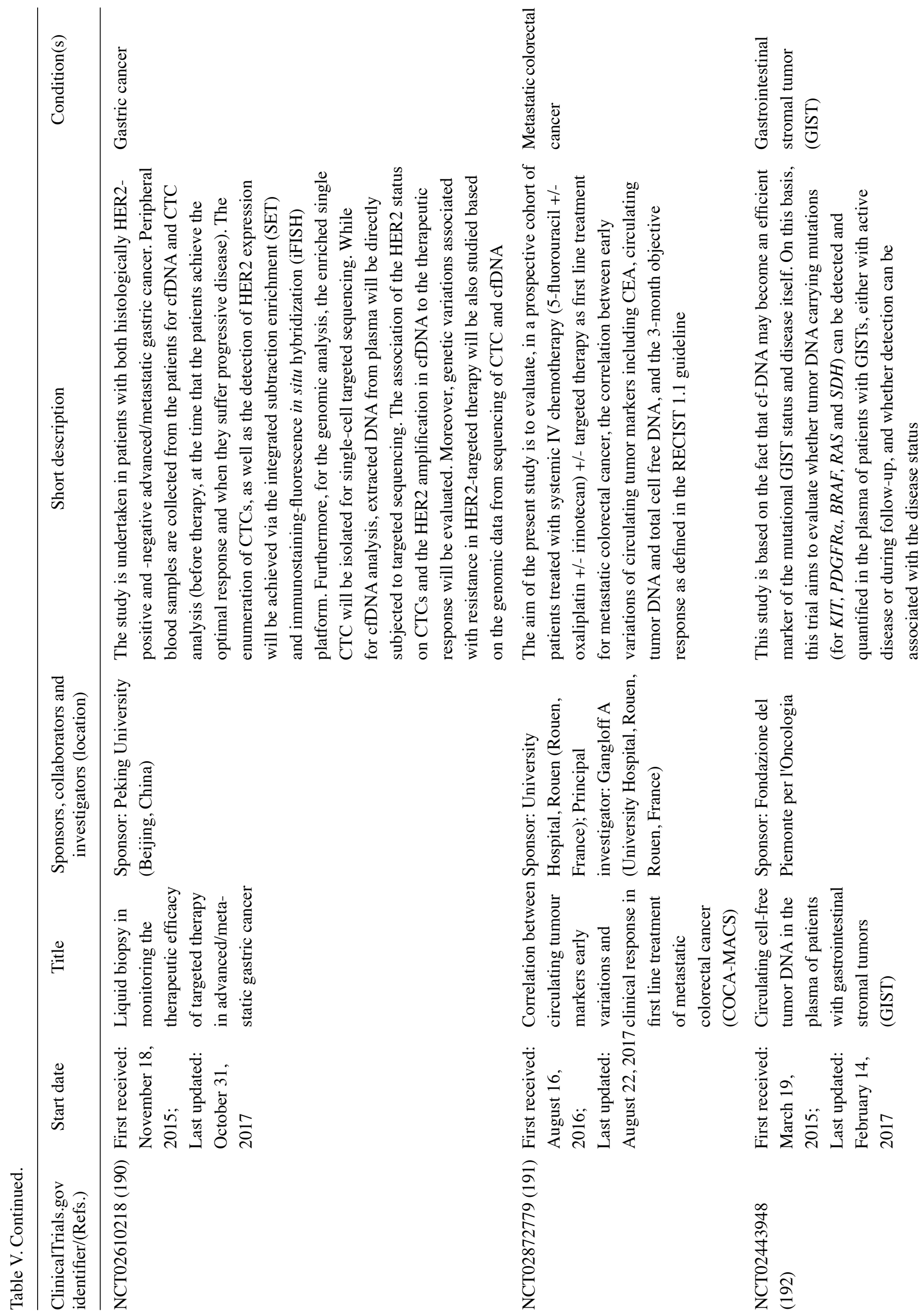




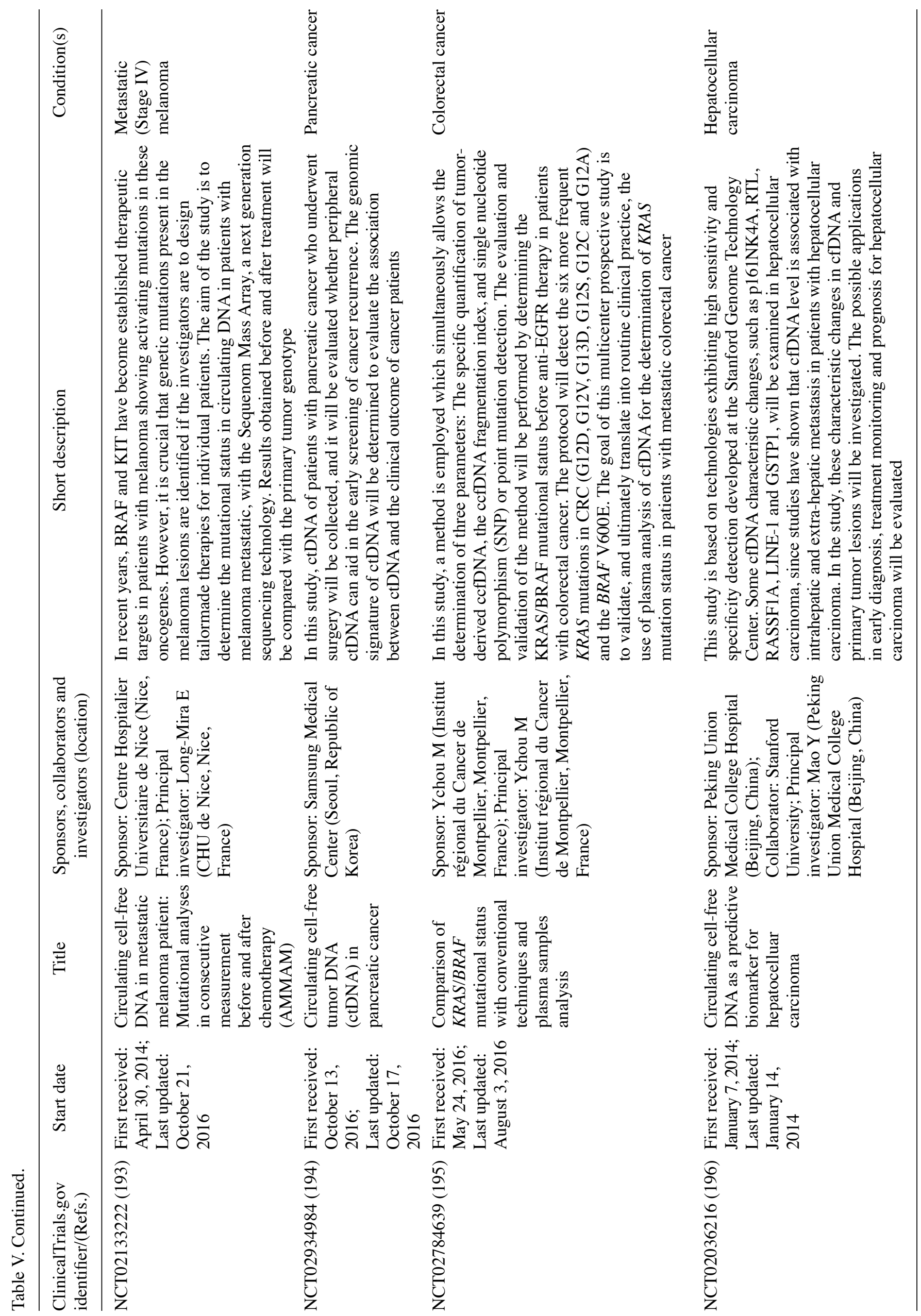




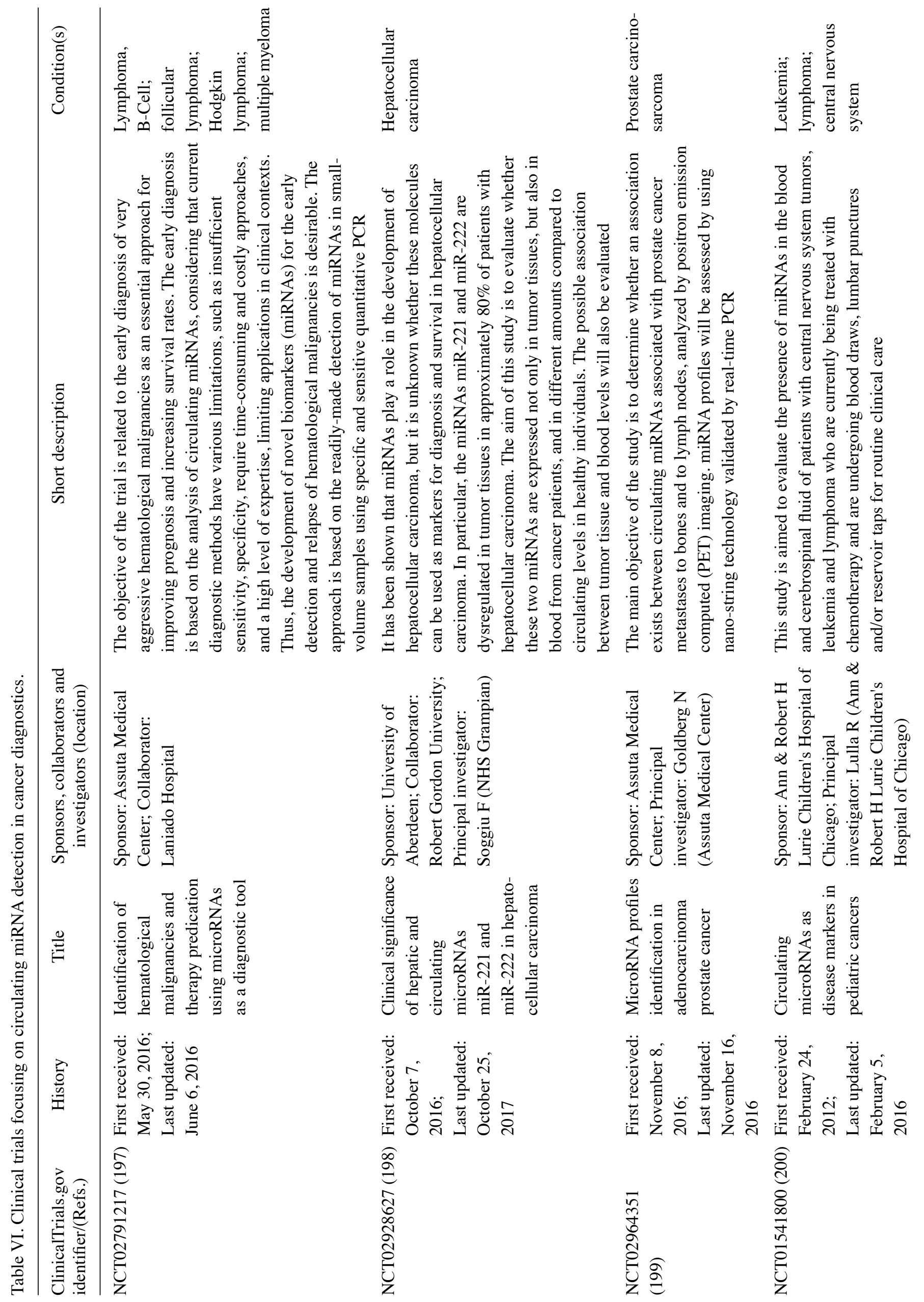




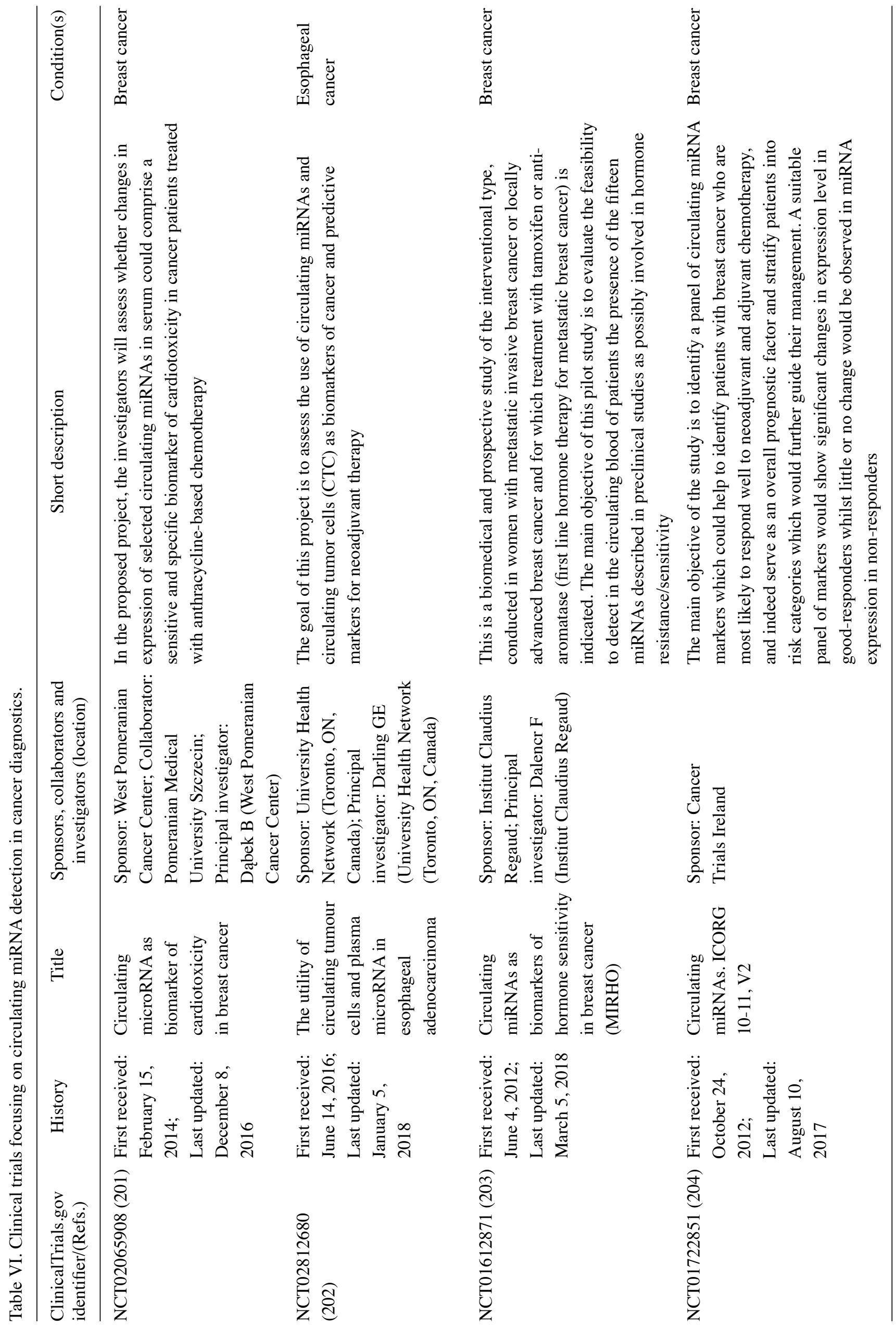


routine clinical practice, the use of plasma analysis of cfDNA for the determination of $K R A S$ mutation status in patients with CRC. Table V lists several examples of ongoing clinical trials based on the analysis of cfDNA in breast, lung, colorectal, stomach, gastric and pancreatic cancers, HCC, non-Hodgkin lymphoma and melanoma.

As regards clinical trials related to miRNAs, one example is NCT02928627 (198), which is focused on miRNAs, such as miR-221 and miR-222, that are both dysregulated in the tumor tissues in approximately $80 \%$ of patients with HCC. The aim of that study was to evaluate whether these two miRNAs are overexpressed not only in tumor tissues, but also in the blood of cancer patients. An association between tumor tissue and blood levels will also be evaluated. Table VI lists additional examples of ongoing clinical trials in breast, esophageal and prostate cancer, HCC, lymphoma and leukemias.

\section{International Networks focusing on liquid biopsy}

The interest in non-invasive tumor diagnosis by liquid biopsy is demonstrated by several international projects supported by public funding. A few selected examples (LIQBIOPSENS, CANCER-ID, PRECISE, BILOBA and ULTRAPLACAD) are reported in the following sections irrespectively of their success in terms of delivered products (manuscripts, validated protocols and platforms, or patents).

LIQBIOPSENS (Reliable Novel Liquid Biopsy technology for early detection of $C R C$ ). This Horizon-2020 project is based on a reliable novel liquid biopsy technology for the early detection of CRC using multidisciplinary approaches involving microelectronics, microfluidics, nanomaterials and genomics. The overall aim of LIQBIOPSENS is the further development and validation in real settings of a novel diagnostic platform for the early and rapid detection of ctDNA and their KRAS and $B R A F$ mutations associated with CRC through blood samples. This sensitive (in the zM range) assay includes $27 K R A S$ and $B R A F$ mutations, to be simultaneously analyzed. Other main features of LIQBIOPSENS are reliability, low-cost and short analysis time. Furthermore, a user-friendly and flexible interface is provided. Among the participants are DestiNA Genomics Ltd. (UK); the Foundation for Research and Technology Hellas, Greece; the Servicio Andaluz del Salud, Spain; BEABLE SL, Spain; Université Catholique de Louvain, Belgium and Sistemas Genomicos SL, Spain (http://liqbiopsens.com).

CANCER-ID (cancer treatment and monitoring through the identification of CTCs and tumor-related nucleic acids in blood). This is a newly formed European consortium funded by the Innovative Medicines Initiative (IMI) with currently 33 partners from 13 countries aiming at the establishment of standard protocols for, and the clinical validation of, bloodbased biomarkers. It brings together experts from academic and clinical research, innovative small-to-medium sized enterprises (SMEs), diagnostics companies and the pharmaceutical industry, thus providing a unique setting for establishing clinical utility of liquid biopsy. The academic leads of the CANCER-ID consortium are Professor Klaus Pantel, Head of the Department of Tumor Biology at the University Medical Center Hamburg-Eppendorf, Hamburg, Germany, and Professor Leon Terstappen, Head of the Department of Medical Cell Biophysics at the University of Twente, Enschede, The Netherlands. The lead companies of the CANCER-ID consortium are Bayer HealthCare and Silicon Biosystems, A Menarini Group Company (http://www.cancer-id.eu).

PRECISE (Personalized Engine for Cancer Integrative Study and Evaluation). This project is an Horizon-2020 pilot project that combines hypothesis-driven strategies with datadriven analysis in a novel mathematical and computational methodology for the integration of genomic, epigenetic, transcriptomic, proteomic and clinical data with the goal of risk-stratifying patients and suggesting personalized therapeutic interventions. As far as motivation is concerned, the PRECISE project is based on the concept that, despite their great promise, high-throughput technologies in cancer research have often failed to translate to major therapeutic advances in clinical practice. One challenge has been tumor heterogeneity, where multiple competing subclones co-exist within a single tumor. Genomic heterogeneity renders it difficult to identify all driving molecular alterations, and thus results in therapies that only target subsets of aggressive tumor cells. Another challenge lies in the integration of multiple types of molecular data into mathematical disease models that can make actionable clinical statements. PRECISE aims to develop predictive computational technology that can exploit molecular and clinical data to improve our understanding of disease mechanisms and to inform clinicians about optimized strategies for therapeutic intervention. The Precise project will focus on two urgent clinical needs in prostate cancer: i) Distinguishing the many indolent tumors from the minority of lethal ones; and ii) providing rationally selected treatment options for patients with advanced disease (http://www.precise-project.eu).

BILOBA (Bloch electromagnetic surface wave biosensors for early cancer diagnosis). BILOBA is a collaborative project funded by the European Commission through its Seventh Framework Program. The major goal of the project is to explore, design and set-up systems optimized for analytical sensing, associated with the development of a corresponding analytical instrument. For this purpose, the immobilization protocols and biochemical assays have been established to ensure an optimized binding site density at the surface of SPR sensors and to enable the detection of the target biomarkers. Furthermore, a fluidic system has been developed for handling the aqueous analyte solutions ensuring a high signal-tonoise ratio and robust results even in the case of ultralow concentrations. The BILOBA multifunctional point-of-care platform is expected to be capable of performing real-time cancer biomarker detection in a tandem configuration. The BILOBA project consists of 9 participants from different European countries, including the Department of Basic and Applied Sciences for Engineering (Università degli Studi di Roma 'La Sapienza', Rome, Italy); the Department of Applied Sciences and Technology (Politecnico di Torino, Torino, Italy); Fraunhofer Gesellschaft, Munich, Germany; the Department of Materials (Imperial College London, London, UK), the Department of Oncology (Università degli Studi di Torino, Torino, Italy); Labor Srl, Rome, Italy; Biotray SAS, Lyon, France; Horiba Jobin Yvon SAS, Paris, France; KDS 
Radeberg GmbH, Dresden, Germany (http://www.bilobaproject.eu/).

ULTRAPLACAD (ULTRAsensitive PLAsmonic devices for early CAncer Diagnosis). With respect to the issue of the detection of cfDNA and miRNAs in tumor liquid biopsies, the highly multidisciplinary ULTRAPLACAD project relies on two advanced plasmonic biosensor technologies: i) Plasmonenhanced fluorescence spectroscopy imaging (PEFSI); and ii) nanostructure-enhanced surface plasmon resonance imaging (NESPRI). Plasmonic methods have already been shown to be useful for biomedical applications for the analysis of nucleic acid analytes in real samples (including human blood) with a limit of detection (LOD) from low femtomolar to attomolar concentrations $(162,205,206)$. In the ULTRAPLACAD project, novel plasmonic structures will be delivered based on surface plasmon modes supported by continuous metallic films and arrays of metallic nanoparticles. Those structures hold the potential for a breakthrough enhancement of sensitivity. Moreover, this method will be implemented in an innovative compact biosensor device based on an integration of key optical elements for the excitation and collecting of fluorescence light directly on the sensor chip. The SPRI approach is based on the detection of target analytes through biomolecular binding-induced refractive index changes. In the ULTRAPLACAD project, an SPRI platform based on the diffraction coupling of light into surface plasmons will be developed, in order to increase sensitivity and limit the signal-to-noise ratios. With respect to the proposed diagnostic model systems, KRAS and $B R A F$ mutations are considered, since they are routinely assessed in genomic DNAs from surgically removed lesions of colorectal carcinoma, breast cancer, melanoma and other tumors. As far as miRNA target sequences are concerned, miR-221, miR-222, miR-141, miR-155, miR-21, let-7a and miR-16 are considered, since these miRNA molecules are available in circulating exosomes, and could mark tumor aggressiveness. ULTRAPLACAD is the only project in which ctDNAs, miRNAs and proteins, e.g., the three major analyte classes, are combined in a single detection platform (www.ultraplacad.eu).

\section{Conclusions}

The liquid biopsy of cancer is mainly based on the analysis of CTCs and/or cell-free nucleic acids in the peripheral blood of cancer patients, as well as in other body fluids suitable for diagnostic assessment. Among these, cerebrospinal fluid for tumors of the central nervous system, saliva for tumors affecting the head and neck, pleural effusion in the case of respiratory tract cancers and urine for urinary tract cancers. At present, liquid biopsy should be considered one of the most advanced non-invasive diagnostic systems suitable for performing key clinically relevant actions possibly leading to precision medicine. Historically, the applications of liquid biopsy for the characterization of cancer patients have been focused on CTCs. More recently, this analysis has been extended to cfDNA and miRNAs, demonstrated to be associated with cancer, with potential applications in early diagnosis, staging, prognosis, prediction of therapeutic responses, therapeutic outcome, and follow-up during therapeutic intervention. Liquid biopsy measures alterations in gene structure, regulation and expres- sion that are the hallmarks of cancer. These analytes include nucleotide variants, promoter methylation, copy number variations of specific genes, chromosomal rearrangements, mutations affecting transcription, splicing and RNA maturation, translational efficiency and differences in miRNA signatures. The analysis of all these parameters can be approached by a variety of technological platforms. Moreover, the great interest of liquid biopsy is that this approach avoids certain key issues associated with invasive surgical biopsy. These include, but are not limited to: i) A static representation of the tumor pathology strictly limited to the tumor tissue sampling; ii) ethical and practical issues preventing repeated tissue biopsy; iii) tumor heterogeneity, particularly during progression and metastatic dissemination (making multiple sampling necessary); iv) easier patient monitoring by non-invasive analytical procedures (i.e., liquid biopsy). Therefore, despite the fact that the liquid biopsy approach suffers from important drawbacks (fragmentation of cfDNA, instability of RNA, low yield of isolated samples to be analyzed and variable presence of normal DNA and RNA) this approach is generally deemed of great interest for future applications, patent development and clinical trials. These will ultimately verify the potential of liquid biopsy in cancer. It is not expected that liquid biopsy will replace surgical biopsy; however, it will probably complement within a few years the information routinely obtained by excisional, incisional, surgical and needle biopsies, becoming a tool of choice for the dynamic monitoring of patients during clinical treatment and during the long-term surveillance of their health status.

\section{Acknowledgements}

Not applicable.

\section{Funding}

This study was supported by the European Union (EU) Horizon 2020 Research and Innovation Programme (GA \#633937, project ULTRAsensitive PLAsmonic devices for early CAncer Diagnosis (ULTRAPLACAD), and by Associazione Italiana per la Ricerca sul Cancro (AIRC) (IG \#13575 to RG, IG\# 14204 and IG \#19052 to PG). MA is the recipient of an AIRC, Nuvenia Fellowship id. 19503.

\section{Availability of data and materials}

Not applicable.

\section{Authors' contributions}

All authors were involved in the conception of the study, and revised and approved the final manuscript. All authors take the responsibility for publishing this review paper. AF, PG, GS and RG performed the literature search, wrote the manuscript, and critically analyzed the existing knowledge; AF and RG designed the figures; AF, MA, JG and RG have ideated and drew the tables; AF, JG and RG were involved in the acquisition of data and in the analysis of patents and clinical trials; JG and MA significantly contributed to editing the manuscript; PG, DAS, GS and RG significantly contributed to the analyses of international networks focusing on liquid biopsy. AF, PG, 
DAS, GS and RG were significantly involved in the drafting of the manuscript.

\section{Ethics approval and consent to participate}

Not applicable.

\section{Patient consent for publication}

Not applicable.

\section{Competing interests}

DAS is the Editor-in-Chief for the journal, but had no personal involvement in the reviewing process, or any influence in terms of adjudicating on the final decision, for this article.

\section{References}

1. Heitzer E, Auer M, Ulz P, Geigl JB and Speicher MR: Circulating tumor cells and DNA as liquid biopsies. Genome Med 5: 73, 2013

2. Bettegowda C, Sausen M, Leary RJ, Kinde I, Wang Y, Agrawal N, Bartlett BR, Wang H, Luber B, Alani RM, et al: Detection of circulating tumor DNA in early- and late-stage human malignancies. Sci Transl Med 6: 224ra24, 2014.

3. Domínguez-Vigil IG, Moreno-Martínez AK, Wang JY Roehrl MHA and Barrera-Saldaña HA: The dawn of the liquid biopsy in the fight against cancer. Oncotarget 9: 2912-2922, 2017.

4. Breitbach S, Tug S, Helmig S, Zahn D, Kubiak T, Michal M, Gori T, Ehlert T, Beiter T and Simon P: Direct quantification of cell-free, circulating DNA from unpurified plasma. PloS One 9: e87838, 2014.

5. Heitzer E, Ulz P and Geigl JB: Circulating tumor DNA as a liquid biopsy for cancer. Clin Chem 61: 112-123, 2015.

6. Yang M, Forbes ME, Bitting RL, O'Neill SS, Chou PC, Topaloglu U, Miller LD, Hawkins GA, Grant SC, DeYoung BR, et al: Incorporating blood-based liquid biopsy information into cancer staging: Time for a TNMB system? Ann Oncol 29:311-323, 2018.

7. Kleppe M and Levine RL: Tumor heterogeneity confounds and illuminates: Assessing the implications. Nat Med 20: 342-344, 2014.

8. Diehl F, Schmidt K, Choti MA, Romans K, Goodman S, Li M, Thornton K, Agrawal N, Sokoll L, Szabo SA, et al: Circulating mutant DNA to assess tumor dynamics. Nat Med 14: 985-990, 2008.

9. Leon SA, Shapiro B, Sklaroff DM and Yaros MJ: Free DNA in the serum of cancer patients and the effect of therapy. Cancer Res 37: 646-650, 1977.

10. Burz C, Pop VV, Buiga R, Daniel S, Samasca G, Aldea C and Lupan I: Circulating tumor cells in clinical research and monitoring patients with colorectal cancer. Oncotarget 9: 24561-24571, 2018.

11. Sozzi G, Conte D, Mariani L, Lo Vullo S, Roz L, Lombardo C, Pierotti MA and Tavecchio L: Analysis of circulating tumor DNA in plasma at diagnosis and during follow-up of lung cancer patients. Cancer Res 61: 4675-4678, 2001.

12. Spindler KL, Pallisgaard N, Vogelius I and Jakobsen A: Quantitative cell-free DNA, KRAS, and BRAF mutations in plasma from patients with metastatic colorectal cancer during treatment with cetuximab and irinotecan. Clin Cancer Res 18 $1177-1185,2012$

13. Perkins G, Yap TA, Pope L, Cassidy AM, Dukes JP, Riisnaes R, Massard C, Cassier PA, Miranda S, Clark J, et al: Multi-purpose utility of circulating plasma DNA testing in patients with advanced cancers. PloS One 7: e47020, 2012

14. Ignatiadis M, Lee M and Jeffrey SS: Circulating tumor cells and circulating tumor DNA: Challenges and opportunities on the path to clinical utility. Clin Cancer Res 21: 4786-4800, 2015.

15. Krebs MG, Hou JM, Ward TH, Blackhall FH and Dive C: Circulating tumour cells: Their utility in cancer management and predicting outcomes. Ther Adv Med Oncol 2: 351-365, 2010 .
16. Millner LM, Linder MW and Valdes R Jr: Circulating tumor cells: a review of present methods and the need to identify heterogeneous phenotypes. Ann Clin Lab Sci 43: 295-304, 2013.

17. Kuipers EJ and Spaander MC: Personalized screening for colorectal cancer. Nat Rev Gastroenterol Hepatol 15: 391-392, 2018.

18. Kloten V, Rüchel N, Brüchle NO, Gasthaus J, Freudenmacher N, Steib F, Mijnes J, Eschenbruch J, Binnebösel M, Knüchel R, et al: Liquid biopsy in colon cancer: Comparison of different circulating DNA extraction systems following absolute quantification of KRAS mutations using Intplex allele-specific PCR Oncotarget 8: 86253-86263, 2017.

19. Thomsen CEB, Appelt AL, Andersen RF, Lindebjerg J, Jensen LH and Jakobsen A: The prognostic value of simultaneous tumor and serum RAS/RAF mutations in localized colon cancer. Cancer Med 6: 928-936, 2017.

20. Spindler KL, Pallisgaard N, Andersen RF, Brandslund I and Jakobsen A: Circulating free DNA as biomarker and source for mutation detection in metastatic colorectal cancer. PLoS One 10: e0108247, 2015.

21. Hardingham JE, Grover P, Winter M, Hewett PJ, Price TJ and Thierry B: Detection and clinical significance of circulating tumor cells in colorectal cancer-20 years of progress. Mol Med 21: S25-S31, 2015.

22. Veldore VH, Choughule A, Routhu T, Mandloi N, Noronha V, Joshi A, Dutt A, Gupta R, Vedam R and Prabhash K: Validation of liquid biopsy: Plasma cell-free DNA testing in clinical management of advanced non-small cell lung cancer. Lung Cancer (Auckl) 9: 1-11, 2018.

23. Anfossi S, Babayan A, Pantel K and Calin GA: Clinical utility of circulating non-coding RNAs - an update. Nat Rev Clin Oncol: May 21, 2018 (Epub ahead of print). doi: 10.1038/s41571018-0035-x.

24. Izzotti A, Carozzo S, Pulliero A, Zhabayeva D, Ravetti JL and Bersimbaev R: Extracellular MicroRNA in liquid biopsy: Applicability in cancer diagnosis and prevention. Am J Cancer Res 6: 1461-1493, 2016.

25. Coombs CC, Zehir A, Devlin SM, Kishtagari A, Syed A, Jonsson P, Hyman DM, Solit DB, Robson ME, Baselga J, et al: Therapy-related clonal hematopoiesis in patients with non-hematologic cancers is common and associated with adverse clinical outcomes. Cell Stem Cell 21: 374-382.e4, 2017.

26. Taly V, Pekin D, Benhaim L, Kotsopoulos SK, Le Corre D, Li X, Atochin I, Link DR, Griffiths AD, Pallier K, et al: Multiplex picodroplet digital PCR to detect KRAS mutations in circulating DNA from the plasma of colorectal cancer patients. Clin Chem 59: 1722-1731, 2013.

27. Wang JY, Hsieh JS, Chang MY, Huang TJ, Chen FM, Cheng TL, Alexandersen K, Huang YS, Tzou WS and Lin SR: Molecular detection of APC, K- ras, and p53 mutations in the serum of colorectal cancer patients as circulating biomarkers. World J Surg 28: 721-726, 2004.

28. Mohan S, Heitzer E, Ulz P, Lafer I, Lax S, Auer M, Pichler M, Gerger A, Eisner F, Hoefler G, et al: Changes in colorectal carcinoma genomes under anti-EGFR therapy identified by whole-genome plasma DNA sequencing. PLoS Genet 10: e1004271, 2014.

29. Feng WN, Gu WQ, Zhao N, Pan YM, Luo W, Zhang H, Liang JM, Yang $J$ and Deng YM: Comparison of the SuperARMS and Droplet Digital PCR for detecting EGFR mutation in ctDNA from NSCLC patients. Transl Oncol 11: 542-545, 2018.

30. Newman AM, Bratman SV, To J, Wynne JF, Eclov NC, Modlin LA, Liu CL, Neal JW, Wakelee HA, Merritt RE, et al: An ultrasensitive method for quantitating circulating tumor DNA with broad patient coverage. Nat Med 20: 548-554, 2014.

31. Fujiwara K, Fujimoto N, Tabata M, Nishii K, Matsuo K, Hotta K, Kozuki T, Aoe M, Kiura K, Ueoka H, et al: Identification of epigenetic aberrant promoter methylation in serum DNA is useful for early detection of lung cancer. Clin Cancer Res 11: $1219-1225,2005$

32. Szpechcinski A, Chorostowska-Wynimko J, Struniawski R, Kupis W, Rudzinski P, Langfort R, Puscinska E, Bielen P, Sliwinski P and Orlowski T: Cell-free DNA levels in plasma of patients with non-small-cell lung cancer and inflammatory lung disease. Br J Cancer. 113: 476-483, 2015.

33. Pisanic TR 2nd, Athamanolap P, Poh W, Chen C, Hulbert A, Brock MV, Herman JG and Wang TH: DREAMing: A simple and ultrasensitive method for assessing intratumor epigenetic heterogeneity directly from liquid biopsies. Nucleic Acids Res 43: e154, 2015 
34. Dawson SJ, Tsui DW, Murtaza M, Biggs H, Rueda OM, Chin SF, Dunning MJ, Gale D, Forshew T, Mahler-Araujo B, et al: Analysis of circulating tumor DNA to monitor metastatic breast cancer. N Engl J Med 368: 1199-209, 2013.

35. Murtaza M, Dawson SJ, Tsui DW, Gale D, Forshew T, Piskorz AM, Parkinson C, Chin SF, Kingsbury Z, Wong AS, et al: Non-invasive analysis of acquired resistance to cancer therapy by sequencing of plasma DNA. Nature 497: 108-112, 2013.

36. Yanagawa T, Kagara N, Miyake T, Tanei T, Naoi Y, Shimoda M, Shimazu K, Kim SJ and Noguchi S: Detection of ESR1 mutations in plasma and tumors from metastatic breast cancer patients using next-generation sequencing. Breast Cancer Res Treat 163 : 231-240, 2017.

37. Mastoraki S, Strati A, Tzanikou E, Chimonidou M, Politaki E, Voutsina A, Psyrri A, Georgoulias V and Lianidou E: ESR1 Methylation: A liquid biopsy-based epigenetic assay for the follow-up of patients with metastatic breast cancer receiving endocrine treatment. Clin Cancer Res 24: 1500-1510, 2018.

38. Gray ES, Rizos H, Reid AL, Boyd SC, Pereira MR, Lo J, Tembe V, Freeman J, Lee JH, Scolyer RA, et al: Circulating tumor DNA to monitor treatment response and detect acquired resistance in patients with metastatic melanoma. Oncotarget 6 : 42008-42018, 2015.

39. Schreuer M, Meersseman G, Van Den Herrewegen S, Jansen Y, Chevolet I, Bott A, Wilgenhof S, Seremet T, Jacobs B, Buyl R, et al: Quantitative assessment of BRAF V600 mutant circulating cell-free tumor DNA as a tool for therapeutic monitoring in metastatic melanoma patients treated with BRAF/MEK inhibitors. J Transl Med 14: 95, 2016.

40. Madic J,Piperno-Neumann S, Servois V, Rampanou A, Milder M Trouiller B, Gentien D, Saada S, Assayag F, Thuleau A, et al: Pyrophosphorolysis-activated polymerization detects circulating tumor DNA in metastatic uveal melanoma. Clin Cancer Res 18 : 3934-3941, 2012

41. Pereira E, Camacho-Vanegas O, Anand S, Sebra R, Catalina Camacho S, Garnar-Wortzel L, Nair N, Moshier E, Wooten M, Uzilov A, et al: Personalized Circulating Tumor DNA Biomarkers dynamically predict treatment response and survival in gynecologic cancers. PLoS One 10: e0145754, 2015.

42. Forshew T, Murtaza M, Parkinson C, Gale D, Tsui DW, Kaper F, Dawson SJ, Piskorz AM, Jimenez-Linan M, Bentley D, et al: Noninvasive identification and monitoring of cancer mutations by targeted deep sequencing of plasma DNA. Sci Transl Med 4 136ra68, 2012.

43. No JH, Kim K, Park KH and Kim YB: Cell-free DNA level as a prognostic biomarker for epithelial ovarian cancer. Anticancer Res 32: 3467-3471, 2012.

44. Giannopoulou L, Chebouti I, Pavlakis K, Kasimir-Bauer S and Lianidou ES: RASSF1A promoter methylation in high-grade serous ovarian cancer: A direct comparison study in primary tumors, adjacent morphologically tumor cell-free tissues and paired circulating tumor DNA. Oncotarget 8: 21429-21443, 2017.

45. Chan KC, Jiang P, Zheng YW, Liao GJ, Sun H, Wong J, Siu SS, Chan WC, Chan SL, Chan AT, et al: Cancer genome scanning in plasma: Detection of tumor-associated copy number aberrations, single-nucleotide variants, and tumoral heterogeneity by massively parallel sequencing. Clin Chem 59: 211-224, 2013

46. Zhang P, Wen X, Gu F, Deng X, Li J, Dong J, Jiao J and Tian Y: Methylation profiling of serum DNA from hepatocellular carcinoma patients using an Infinium Human Methylation 450 BeadChip. Hepatol Int 7: 893-900, 2013.

47. Ren N, Qin LX, Tu H, Liu YK, Zhang BH and Tang ZY: The prognostic value of circulating plasma DNA level and its allelic imbalance on chromosome $8 \mathrm{p}$ in patients with hepatocellular carcinoma. J Cancer Res Clin Oncol 132: 399-407, 2006

48. Huang A, Zhang X, Zhou SL, Cao Y, Huang XW, Fan J, Yang XR and Zhou J: Detecting circulating tumor DNA in hepatocellular carcinoma patients using Droplet Digital PCR is feasible and reflects intratumoral heterogeneity. J Cancer 7: 1907-1914, 2016.

49. Heitzer E, Ulz P, Belic J, Gutschi S, Quehenberger F, Fischereder K, Benezeder T, Auer M, Pischler C, Mannweiler S, et al: Tumor-associated copy number changes in the circulation of patients with prostate cancer identified through whole-genome sequencing. Genome Med 5: 30, 2013.

50. Annala M, Vandekerkhove G, Khalaf D, Taavitsainen S, Beja K, Warner EW, Sunderland K, Kollmannsberger C, Eigl BJ, Finch D, et al: Circulating tumor DNA genomics correlate with resistance to Abiraterone and Enzalutamide in prostate cancer. Cancer Discov 8: 444-457, 2018.
51. Delgado PO, Alves BC, Gehrke Fde S, Kuniyoshi RK, Wroclavski ML, Del Giglio A and Fonseca FL: Characterization of cell-free circulating DNA in plasma in patients with prostate cancer. Tumour Biol 34: 983-986, 2013.

52. Buelens S, Claeys T, Dhondt B, Poelaert F, Vynck M, Yigit N, Thas O, Ost P, Vandesompele J, Lumen N, et al: Prognostic and therapeutic implications of circulating androgen receptor gene copy number in prostate cancer patients using Droplet Digital polymerase chain reaction. Clin Genitourin Cancer 16: 197-205, 2017.

53. Pu XX, Huang GL, Guo HQ, Guo CC, Li H, Ye S, Ling S, Jiang L, Tian Y and Lin TY: Circulating miR-221 directly amplified from plasma is a potential diagnostic and prognostic marker of colorectal cancer and is correlated with p53 expression. J Gastroenterol Hepatol 25: 1674-1680, 2010.

54. Liu GH, Zhou ZG, Chen R, Wang MJ, Zhou B, Li Y and Sun XF: Serum miR-21 and miR-92a as biomarkers in the diagnosis and prognosis of colorectal cancer. Tumour Biol 34: 2175-2181, 2013.

55. Cheng H, Zhang L, Cogdell DE, Zheng H, Schetter AJ, Nykter M, Harris CC, Chen K, Hamilton SR and Zhang W: Circulating plasma miR-141 is a novel biomarker for metastatic colon cancer and predicts poor prognosis. PLoS One 6: e17745, 2011.

56. Lv ZC, Fan YS, Chen HB and Zhao DW: Investigation of microRNA-155 as a serum diagnostic and prognostic biomarker for colorectal cancer. Tumour Biol 36: 1619-1625, 2015.

57. Krawczyk P, Powrózek T, Olesiński T, Dmitruk A, Dziwota J, Kowalski D and Milanowski J: Evaluation of miR-506 and miR-4316 expression in early and non-invasive diagnosis of colorectal cancer. Int J Colorectal Dis 32: 1057-1060, 2017.

58. Huang Z, Huang D, Ni S, Peng Z, Sheng W and Du X: Plasma microRNAs are promising novel biomarkers for early detection of colorectal cancer. Int J Cancer 127: 118-126, 2010.

59. Liu C, Eng C, Shen J, Lu Y, Takata Y, Mehdizadeh A, Chang GJ, Rodriguez-Bigas MA, Li Y, Chang P, et al: Serum exosomal miR-4772-3p is a predictor of tumor recurrence in stage II and III colon cancer. Oncotarget 7: 76250-76260, 2016.

60. Ogata-Kawata H, Izumiya M, Kurioka D, Honma Y, Yamada Y, Furuta K, Gunji T, Ohta H, Okamoto H, Sonoda H, et al: Circulating exosomal microRNAs as biomarkers of colon cancer. PLoS One 9: e92921, 2014.

61. Ng EK, Chong WW, Jin H, Lam EK, Shin VY, Yu J, Poon TC, Ng SS and Sung JJ: Differential expression of microRNAs in plasma of patients with colorectal cancer: A potential marker for colorectal cancer screening. Gut 58: 1375-1381, 2009.

62. Zheng G, Du L, Yang X, Zhang X, Wang L, Yang Y, Li J and Wang C: Serum microRNA panel as biomarkers for early diagnosis of colorectal adenocarcinoma. Br J Cancer 111: 1985-1992, 2014

63. Dou H, Wang Y, Su G and Zhao S: Decreased plasma let-7c and miR-152 as noninvasive biomarker for non-small-cell lung cancer. Int J Clin Exp Med 8: 9291-9298, 2015.

64. Yu H, Jiang L, Sun C, Li Guo L, Lin M, Huang J and Zhu L: Decreased circulating miR-375: A potential biomarker for patients with non-small-cell lung cancer. Gene 534: 60-65, 2014.

65. Li N, Ma J, Guarnera MA, Fang H, Cai L and Jiang F: Digital PCR quantification of miRNAs in sputum for diagnosis of lung cancer. J Cancer Res Clin Oncol 140: 145-150, 2014.

66. Geng Q, Fan T, Zhang B, Wang W, Xu Y and Hu H: Five microRNAs in plasma as novel biomarkers for screening of early-stage non-small cell lung cancer. Respir Res 15: 149, 2014.

67. Hu Z, Chen X, Zhao Y, Tian T, Jin G, Shu Y, Chen Y, Xu L, Zen K, Zhang C, et al: Serum microRNA signatures identified in a genome-wide serum microRNA expression profiling predict survival of non-small-cell lung cancer. J Clin Oncol 28: $1721-1726,2010$

68. Yu L, Todd NW, Xing L, Xie Y, Zhang H, Liu Z, Fang H, Zhang J, Katz RL and Jiang F: Early detection of lung adenocarcinoma in sputum by a panel of microRNA markers. Int J Cancer 127: 2870-2878, 2010

69. Liu XG, Zhu WY, Huang YY, Ma LN, Zhou SQ, Wang YK, Zeng F, Zhou JH and Zhang YK: High expression of serum miR-21 and tumor miR-200c associated with poor prognosis in patients with lung cancer. Med Oncol 29: 618-626, 2012

70. Leng Q, Lin Y, Jiang F, Lee CJ, Zhan M, Fang H, Wang Y and Jiang F: A plasma miRNA signature for lung cancer early detection. Oncotarget 8: 111902-111911, 2017.

71. Asaga S, Kuo C, Nguyen T, Terpenning M, Giuliano AE and Hoon DS: Direct serum assay for microRNA-21 concentrations in early and advanced breast cancer. Clin Chem 57: 84-91, 2011. 
72. Zhu W, Qin W, Atasoy U and Sauter ER: Circulating microRNAs in breast cancer and healthy subjects. BMC Res Notes 2: 89, 2009.

73. Heneghan HM, Miller N, Lowery AJ, Sweeney KJ, Newell J and Kerin MJ: Circulating microRNAs as novel minimally invasive biomarkers for breast cancer. Ann Surg 251: 499-505, 2010.

74. Stückrath I, Rack B, Janni W, Jäger B, Pantel K and Schwarzenbach H: Aberrant plasma levels of circulating miR-16, miR-107, miR-130a and miR-146a are associated with lymph node metastasis and receptor status of breast cancer patients. Oncotarget 6: 13387-13401, 2015.

75. Mangolini A, Ferracin M, Zanzi MV, Saccenti E, Ebnaof SO, Poma VV, Sanz JM, Passaro A, Pedriali M, Frassoldati A, et al: Diagnostic and prognostic microRNAs in the serum of breast cancer patients measured by droplet digital PCR. Biomark Res 3: 12,2015

76. Kleivi Sahlberg K, Bottai G, Naume B, Burwinkel B, Calin GA, Børresen-Dale AL and Santarpia L: A serum microRNA signature predicts tumor relapse and survival in triple-negative breast cancer patients. Clin Cancer Res 21: 1207-1214, 2015.

77. Margue C, Reinsbach S, Philippidou D, Beaume N, Walters C, Schneider JG, Nashan D, Behrmann I and Kreis S: Comparison of a healthy miRNome with melanoma patient miRNomes: are microRNAs suitable serum biomarkers for cancer? Oncotarget 6: 12110-121127, 2015.

78. Fleming NH, Zhong J, da Silva IP, Vega-Saenz de Miera E Brady B, Han SW, Hanniford D, Wang J, Shapiro RL, Hernando E, et al: Serum-based miRNAs in the prediction and detection of recurrence in melanoma patients. Cancer 121: 51-59, 2015.

79. Ono S, Oyama T, Lam S, Chong K, Foshag LJ and Hoon DS A direct plasma assay of circulating microRNA-210 of hypoxia can identify early systemic metastasis recurrence in melanoma patients. Oncotarget 6: 7053-7064, 2015.

80. Stark MS, Klein K, Weide B, Haydu LE, Pflugfelder A, Tang YH, Palmer JM, Whiteman DC, Scolyer RA, Mann GJ, et al: The prognostic and predictive value of melanoma-related microRNAs using tissue and serum: A microRNA expression analysis. EBioMedicine 2: 671-680, 2015.

81. Friedman EB, Shang S, de Miera EV, Fog JU, Teilum MW, Ma MW, Berman RS, Shapiro RL, Pavlick AC, Hernando E, et al Serum microRNAs as biomarkers for recurrence in melanoma. J Transl Med 10: 155, 2012

82. Kanemaru H, Fukushima S, Yamashita J, Honda N, Oyama R, Kakimoto A, Masuguchi S, Ishihara T, Inoue $\mathrm{Y}$, Jinnin $\mathrm{M}$, et al The circulating microRNA-221 level in patients with malignant melanoma as a new tumor marker. J Dermatol Sci 61: 187-193, 2011.

83. Fogli S, Polini B, Carpi S, Pardini B, Naccarati A, Dubbini N, Lanza M, Breschi MC, Romanini A and Nieri P: Identification of plasma microRNAs as new potential biomarkers with high diagnostic power in human cutaneous melanoma. Tumour Biol 39: 1010428317701646, 2017

84. Yokoi A, Yoshioka Y, Hirakawa A, Yamamoto Y, Ishikawa M, Ikeda S, Kato T, Niimi K, Kajiyama H, Kikkawa F, et al: A combination of circulating miRNAs for the early detection of ovarian cancer. Oncotarget 8: 89811-89823, 2017.

85. Todeschini P, Salviato E, Paracchini L, Ferracin M, Petrillo M, Zanotti L, Tognon G, Gambino A, Calura E, Caratti G, et al: Circulating miRNA landscape identifies miR-1246 as promising diagnostic biomarker in high-grade serous ovarian carcinoma: A validation across two independent cohorts. Cancer Lett 388 : 320-327, 2017

86. Zuberi M, Mir R, Das J, Ahmad I, Javid J, Yadav P, Masroor M, Ahmad S, Ray PC and Saxena A: Expression of serum miR-200a, miR-200b, and miR-200c as candidate biomarkers in epithelial ovarian cancer and their association with clinicopathological features. Clin Transl Oncol 17: 779-787, 2015.

87. Liang H, Jiang Z, Xie G and Lu Y: Serum microRNA-145 as a novel biomarker in human ovarian cancer. Tumour Biol 36 $5305-5313,2015$

88. Gao YC and Wu J. MicroRNA-200c and microRNA-141 as potential diagnostic and prognostic biomarkers for ovarian cancer. Tumour Biol 36: 4843-4850, 2015.

89. Zhou J, Gong G, Tan H, Dai F, Zhu X, Chen Y, Wang J, Liu Y, Chen $\mathrm{P}, \mathrm{Wu} \mathrm{X}$, et al: Urinary microRNA-30a-5p is a potential biomarker for ovarian serous adenocarcinoma. Oncol Rep 33: 2915-2923, 2015.
90. Shah JS, Gard GB, Yang J, Maidens J, Valmadre S, Soon PS and Marsh DJ: Combining serum microRNA and CA-125 as prognostic indicators of preoperative surgical outcome in women with high-grade serous ovarian cancer. Gynecol Oncol 148: 181-188, 2018.

91. Gui J, Tian Y, Wen X, Zhang W, Zhang P, Gao J, Run W, Tian L, Jia $X$ and Gao Y: Serum microRNA characterization identifies miR-885-5p as a potential marker for detecting liver pathologies. Clin Sci (Lond) 120: 183-193, 2011

92. Yamamoto Y, Kosaka N, Tanaka M, Koizumi F, Kanai Y, Mizutani T, Murakami Y, Kuroda M, Miyajima A, Kato T, et al: MicroRNA-500 as a potential diagnostic marker for hepatocellular carcinoma. Biomarkers 14: 529-538, 2009.

93. Xu J, Wu C, Che X, Wang L, Yu D, Zhang T, Huang L, Li H, Tan W, Wang C, et al: Circulating microRNAs, miR-21, miR-122, and miR-223, in patients with hepatocellular carcinoma or chronic hepatitis. Mol Carcinog 50: 136-142, 2011

94. Zhou J, Yu L, Gao X, Hu J, Wang J, Dai Z, Wang JF, Zhang Z, Lu S, Huang X, et al: Plasma microRNA panel to diagnose hepatitis B virus-related hepatocellular carcinoma. J Clin Oncol 29: 4781-4788, 2011.

95.Li LM, Hu ZB, Zhou ZX, Chen X, Liu FY, Zhang JF, Shen HB, Zhang CY and Zen K: Serum microRNA profiles serve as novel biomarkers for HBV infection and diagnosis of HBV-positive hepatocarcinoma. Cancer Res 70: 9798-9807, 2010.

96. Moshiri F, Salvi A, Gramantieri L, Sangiovanni A, Guerriero P, De Petro G, Bassi C, Lupini L, Sattari A, Cheung D, et al: Circulating miR-106b-3p, miR-101-3p and miR-1246 as diagnostic biomarkers of hepatocellular carcinoma. Oncotarget 9: 15350-15364, 2018.

97. Kachakova D, Mitkova A, Popov E, Popov I, Vlahova A, Dikov T, Christova S, Mitev V, Slavov C and Kaneva R: Combinations of serum prostate-specific antigen and plasma expression levels of let-7c, miR-30c, miR-141, and miR-375 as potential better diagnostic biomarkers for prostate cancer. DNA Cell Biol 34: 189-200, 2015

98. Bryant RJ, Pawlowski T, Catto JW, Marsden G, Vessella RL, Rhees B, Kuslich C, Visakorpi T and Hamdy FC: Changes in circulating microRNA levels associated with prostate cancer. $\mathrm{Br}$ J Cancer 106: 768-774, 2012

99.Lin HM, Castillo L, Mahon KL, Chiam K, Lee BY, Nguyen Q, Boyer MJ, Stockler MR, Pavlakis N, Marx G, et al: Circulating microRNAs are associated with docetaxel chemotherapy outcome in castration-resistant prostate cancer. Br J Cancer 110: 2462-2471, 2014

100. Kotb S, Mosharafa A, Essawi M, Hassan H, Meshref A and Morsy A: Circulating miRNAs 21 and 221 as biomarkers for early diagnosis of prostate cancer. Tumour Biol 35: 12613-12617, 2014.

101. Srivastava A, Goldberger H, Dimtchev A, Ramalinga M, Chijioke J, Marian C, Oermann EK, Uhm S, Kim JS, Chen LN, et al: MicroRNA profiling in prostate cancer-the diagnostic potential of urinary miR-205 and miR-214. PLoS One 8: e76994, 2013.

102. Singh PK, Preus L, Hu Q, Yan L, Long MD, Morrison CD, Nesline M, Johnson CS, Koochekpour S, Kohli M, et al: Serum microRNA expression patterns that predict early treatment failure in prostate cancer patients. Oncotarget 5: 824-840, 2014.

103. Farran B, Dyson G, Craig D, Dombkowski A, BeebeDimmer JL, Powell IJ, Podgorski I, Heilbrun L, Bolton S and Bock $\mathrm{CH}$ : A study of circulating microRNAs identifies a new potential biomarker panel to distinguish aggressive prostate cancer. Carcinogenesis 39: 556-561, 2018.

104. Cochetti G, Poli G, Guelfi G, Boni A, Egidi MG and Mearini E: Different levels of serum microRNAs in prostate cancer and benign prostatic hyperplasia: Evaluation of potential diagnostic and prognostic role. Onco Targets Ther 9: 7545-7553, 2016.

105. Brychta N, Krahn T and von Ahsen O: Detection of KRAS mutations in circulating tumor DNA by digital PCR in early stages of pancreatic cancer. Clin Chem 62: 1482-1491, 2016.

106. Kinugasa H, Nouso K, Miyahara K, Morimoto Y, Dohi C, Tsutsumi K, Kato H, Matsubara T, Okada $\mathrm{H}$ and Yamamoto $\mathrm{K}$ : Detection of K-ras gene mutation by liquid biopsy in patients with pancreatic cancer. Cancer 121: 2271-2280, 2015.

107. Couraud S, Zalcman G, Milleron B, Morin F and Souquet PJ: Lung cancer in never smokers-a review. Eur J Cancer 48: 1299-1311, 2012 . 
108.Perez-Carbonell L, Sinicrope FA, Alberts SR, Oberg AL, Balaguer F, Castells A, Boland CR and Goel A: miR-320e is a novel prognostic biomarker in colorectal cancer. Br J Cancer 113: 83-90, 2015.

109. Case M, Matheson E, Minto L, Hassan R, Harrison CJ, Bown N, Bailey S, Vormoor J, Hall AG and Irving JA: Mutation of genes affecting the RAS pathway is common in childhood acute lymphoblastic leukemia. Cancer Res 68: 6803-6809, 2008.

110. Lin CC, Huang WL, Wei F, Su WC and Wong DT: Emerging platforms using liquid biopsy to detect EGFR mutations in lung cancer. Expert Rev Mol Diagn 15: 1427-1440, 2015.

111. Warton K, Mahon KL and Samimi G: Methylated circulating tumor DNA in blood: Power in cancer prognosis and response. Endocr Relat Cancer 23: R157-171, 2016.

112. Mitchell SM,Ho T, Brown GS, BakerRT, Thomas ML, McEvoy A, $\mathrm{Xu} \mathrm{ZZ}$, Ross JP, Lockett TJ, Young GP, et al: Evaluation of methylation biomarkers for detection of crculating tumor DNA and application to colorectal cancer. Genes (Basel) 7: E125, 2016.

113. Ghelani HS, Rachchh MA and Gokani RH: MicroRNAs as newer therapeutic targets: A big hope from a tiny player. J Pharmacol Pharmacother 3: 217-227, 2012.

114. Krol J, Loedige I and Filipowicz W: The widespread regulation of microRNA biogenesis, function and decay. Nat Rev Genet 11: $597-610,2010$

115. Sun K and Lai EC: Adult-specific functions of animal microRNAs. Nat Rev Genet 14: 535-548, 2013.

116. Chekulaeva M and Filipowicz W: Mechanisms of miRNAmediated post-transcriptional regulation in animal cells. Curr Opin Cell Biol 21: 452-460, 2009.

117. Guo H, Ingolia NT, Weissman JS and Bartel DP: Mammalian microRNAs predominantly act to decrease target mRNA levels. Nature 466: 835-840, 2010.

118. Cammaerts S, Strazisar M, De Rijk P and Del Favero J: Genetic variants in microRNA genes: Impact on microRNA expression, function, and disease. Front Genet 6: 186, 2015.

119. Friedländer MR, Lizano E, Houben AJS, Bezdan D, BáñezCoronel M and Kudla G: Evidence for the biogenesis of more than 1,000 novel human microRNAs. Genome Biol 15: R57, 2014.

120.Cheng WC, Chung IF, Tsai CF, Huang TS, Chen CY and Wang SC: YM500v2: A small RNA sequencing (smRNA-seq) database for human cancer miRNome research. Nucleic Acids Res 43: D862-D867, 2015.

121. Londin E, Loher P, Telonis AG, Quann K, Clark P and Jing Y: Analysis of 13 cell types reveals evidence for the expression of numerous novel primate-and tissue-specific microRNAs. Proc Natl Acad Sci USA 112: E1106-E1115, 2015.

122. Griffiths-Jones S, Grocock RJ, van Dongen S, Bateman A and Enright AJ: miRBase: MicroRNA sequences, targets and gene nomenclature. Nucleic Acids Res 34: D140-D144, 2006.

123. Gambari R, Fabbri E, Borgatti M, Lampronti I, Finotti A, Brognara E, Bianchi N, Manicardi A, Marchelli R and Corradini R: Targeting microRNAs involved in human diseases: A novel approach for modification of gene expression and drug development. Biochem Pharmacol 82: 1416-1429, 2011.

124.Piva R, Spandidos DA and Gambari R: From microRNA functions to microRNA therapeutics: Novel targets and novel drugs in breast cancer research and treatment. Int J Oncol 43: 985-994, 2013.

125. Gambari R, Brognara E, Spandidos DA and Fabbri E: Targeting oncomiRNAs and mimicking tumor suppressor miRNAs: New trends in the development of miRNA therapeutic strategies in oncology. Int J Oncol 49: 5-32, 2016.

126. Bertucci A, Prasetyanto EA, Septiadi D, Manicardi A Brognara E, Gambari R, Corradini R and De Cola L: Combined Delivery of temozolomide and anti-miR221 PNA using mesoporous silica nanoparticles induces apoptosis in resistant glioma cells. Small 11: 5687-5695, 2015.

127. Gheinani AH, Vögeli M, Baumgartner U, Vassella E, Draege rA, Burkhard FC and Monastyrskaya K: Improved isolation strategies to increase the yield and purity of human urinary exosomes for biomarker discovery. Sci Rep 8: 3945 , 2018.

128.da Silveira JC, Andrade GM, Del Collado M, Sampaio RV, Sangalli JR, Silva LA, Pinaffi FVL, Jardim IB, Cesar MC, Nogueira MFG, et al: Supplementation with small-extracellular vesicles from ovarian follicular fluid during in vitro production modulates bovine embryo development. PLoS One 12: e0179451, 2017.
129. Halvorsen AR, Helland Å, Gromov P, Wielenga VT, Talman MM, Brunner N, Sandhu V, Børresen-Dale AL, Gromova I and Haakensen VD: Profiling of microRNAs in tumor interstitial fluid of breast tumors - a novel resource to identify biomarkers for prognostic classification and detection of cancer. Mol Oncol 11: 220-234, 2017.

130. Valentino A, Reclusa P, Sirera R, Giallombardo M, Camps C, Pauwels P, Crispi S and Rolfo C: Exosomal microRNAs in liquid biopsies: Future biomarkers for prostate cancer. Clin Transl Oncol 19: 651-657, 2017.

131. Wecker T, Hoffmeier K, Plötner A, Grüning BA, Horres R, Backofen R, Reinhard T and Schlunck G: MicroRNA profiling in aqueous humor of individual human eyes by next-generation sequencing. Invest Ophthalmol Vis Sci 57: 1706-1713, 2016.

132. Nishida-Aoki $\mathrm{N}$ and Ochiya T: Interactions between cancer cells and normal cells via miRNAs in extracellular vesicles. Cell Mol Life Sci 72: 1849-1861, 2015

133. Schetter AJ, Okayama H and Harris CC: The role of microRNAs in colorectal cancer. Cancer J 18: 244-252, 2012.

134. Markowitz SD and Bertagnolli MM: Molecular origins of cancer: Molecular basis of colorectal cancer. N Engl J Med 361: 2449-2460, 2009.

135. Bellassai $\mathrm{N}$ and Spoto G: Biosensors for liquid biopsy: Circulating nucleic acids to diagnose and treat cancer. Anal Bioanal Chem 408: 7255-7264, 2016.

136. Das J, Ivanov I, Montermini L, Rak J, Sargent EH and Kelley SO: An electrochemical clamp assay for direct, rapid analysis of circulating nucleic acids in serum. Nat Chem 7: $569-575,2015$.

137. Pinheiro LB, Coleman VA, Hindson CM, Herrmann J, Hindson BJ, Bhat S and Emslie KR: Evaluation of a Droplet Digital polymerase chain reaction format for DNA copy number quantification. Anal Chem 84: 1003-1011, 2012.

138. Podlesniy P and Trullas R: Biomarkers in cerebrospinal fluid: Analysis of cell-free circulating mitochondrial DNA by digital PCR. Methods Mol Biol 1768: 111-126, 2018.

139. Macagno N, Fina F, Penel N, Bouvier C, Nanni I, Duffaud F, Rouah R, Lacarelle B, Ouafik L, Bonvalot S, et al: Proof of concept: Prognostic value of the plasmatic concentration of circulating cell free DNA in desmoid tumors using ddPCR. Oncotarget 9: 18296-18308, 2018.

140.DiNardo CD, Routbort MJ, Bannon SA, Benton CB, Takahashi K, Kornblau SM, Luthra R, Kanagal-Shamanna R, Medeiros LJ, Garcia-Manero G, et al: Improving the detection of patients with inherited predispositions to hematologic malignancies using next-generation sequencing-based leukemia prognostication panels. Cancer 124: 2704-2713, 2018.

141. Müllauer L: Next generation sequencing: Clinical applications in solid tumours. Memo 10: 244-247, 2017.

142. Giuffrida MC and Spoto G: Integration of isothermal amplification methods in microfluidic devices: Recent advances. Biosens Bioelectron 90: 174-186, 2017.

143. Giuffrida MC, Zanoli LM, D'Agata R, Finotti A, Gambari $\mathrm{R}$ and Spoto G: Isothermal circular-strand-displacement polymerization of DNA and microRNA in digital microfluidic devices. Anal Bioanal Chem 407: 1533-1543, 2015.

144. Garcia-Olmo DC, Gutierrez-Gonzalez L, Ruiz-Piqueras R, Picazo MG and Garcia-Olmo D: Detection of circulating tumor cells and of tumor DNA in plasma during tumor progression in rats. Cancer Lett 217: 115-123, 2005.

145. Rago C, Huso DL, Diehl F, Karim B, Liu G, Papadopoulos N, Samuels Y, Velculescu VE, Vogelstein B, Kinzler KW, et al: Serial assessment of human tumor burdens in mice by the analysis of circulating DNA. Cancer Res 67: 9364-9370, 2007.

146. Thierry AR, Mouliere F, Gongora C, Ollier J, Robert B, Ychou M, Del Rio M and Molina F: Origin and quantification of circulating DNA in mice with human colorectal cancer xenografts. Nucleic Acids Res 38: 6159-6175, 2010.

147. Mitchell PS, Parkin RK, Kroh EM, Fritz BR, Wyman SK, Pogosova-Agadjanyan EL, Peterson A, Noteboom J, O'Briant KC, Allen A, et al: Circulating microRNAs as stable blood-based markers for cancer detection. Proc Natl Acad Sci US A 105: 10513-10518, 2008.

148. Selth LA, Townley S, Gillis JL, Ochnik AM, Murti K, Macfarlane RJ, Chi KN, Marshall VR, Tilley WD and Butler LM: Discovery of circulating microRNAs associated with human prostate cancer using a mouse model of disease. Int J Cancer 131: 652-661, 2012. 
149. Waters PS, McDermott AM, Wall D, Heneghan HM, Miller N, Newell J, Kerin MJ and Dwyer RM: Relationship between circulating and tissue microRNAs in a murine model of breast cancer. PLoS One 7: e50459, 2012.

150. Greystoke A, Ayub M, Rothwell DG, Morris D, Burt D, Hodgkinson CL, Morrow CJ, Smith N, Aung K, Valle J, et al: Development of a circulating miRNA assay to monitor tumor burden: From mouse to man. Mol Oncol 10: 282-291, 2016.

151. Gasparello J, Allegretti M, Tremante E, Fabbri E, Amoreo CA, Romania P, Melucci E, Messana K, Borgatti M, Giacomini P, et al: Liquid biopsy in mice bearing colorectal carcinoma xenografts: Gateways regulating the levels of circulating tumor DNA (ctDNA) and miRNA (ctmiRNA). J Exp Clin Cancer Res 37: $124,2018$.

152. Hofman P: Liquid biopsy for early detection of lung cancer. Curr Opin Oncol 29: 73-78, 2017.

153. Pérez-Ramírez C, Cañadas-Garre M, Robles AI, Molina MÁ, Faus-Dáder MJ and Calleja-Hernández MÁ: Liquid biopsy in early stage lung cancer. Transl Lung Cancer Res 5: 517-524, 2016.

154. Bedin C, Enzo MV, Del Bianco P, Pucciarelli S, Nitti D and Agostini M: Diagnostic and prognostic role of cell-free DNA testing for colorectal cancer patients. Int J Cancer 140 1888-1898, 2017.

155. Allenson K, Castillo J, San Lucas FA, Scelo G, Kim DU, Bernard V, Davis G, Kumar T, Katz M, Overman MJ, et al: High prevalence of mutant KRAS in circulating exosome-derived DNA from early-stage pancreatic cancer patients. Ann Oncol 28: 741-747, 2017.

156. Shimomura A, Shiino S, Kawauchi J, Takizawa S, Sakamoto H, Matsuzaki J, Ono M, Takeshita F, Niida S, Shimizu C, et al: Novel combination of serum microRNA for detecting breas cancer in the early stage. Cancer Sci 107: 326-334, 2016.

157. Schröck A, Leisse A, de Vos L, Gevensleben H, Dröge F, Franzen A, Wachendörfer M, Schröck F, Ellinger J, Teschke M, et al: Free-circulating methylated DNA in blood for diagnosis, staging, prognosis, and monitoring of head and neck squamous cell carcinoma patients: An observational prospective cohort study. Clin Chem 63: 1288-1296, 2017.

158. Quandt D, Dieter Zucht H, Amann A, Wulf-Goldenberg A, Borrebaeck C, Cannarile M, Lambrechts D, Oberacher H, Garrett J, Nayak T, et al: Implementing liquid biopsies into clinical decision making for cancer immunotherapy. Oncotarget 8: 48507-48520, 2018.

159. Goodall J, Mateo J, Yuan W, Mossop H, Porta N, Miranda S, Perez-Lopez R, Dolling D, Robinson DR, Sandhu S, et al: Circulating cell-free DNA to quide prostate cancer treatment with PARP inhibition. Cancer Discov 7: 1006-1017, 2017.

160. He J, Tan W and Ma J: Circulating tumor cells and DNA for real-time EGFR detection and monitoring of non-small-cell lung cancer. Future Oncol 13: 787-797, 2017.

161. Craw P and Balachandran W: Isothermal nucleic acid amplification technologies for point-of-care diagnostics: A critical review. Lab Chip 12: 2469-2486, 2012

162.Kim J and Easley CJ: Isothermal DNA amplification in bioanalysis: strategies and applications. Bioanalysis 3: 227-239, 2011

163. Guo Q, Yang X, Wang K, Tan W, Li W, Tang H and Li H: Sensitive fluorescence detection of nucleic acids based on isothermal circular strand-displacement polymerization reaction. Nucleic Acids Res 37: e20, 2009.

164. D'Agata R, Breveglieri G, Zanoli LM, Borgatti M, Spoto G and Gambari R: Direct detection of point mutations in nonamplified human genomic DNA. Anal Chem 83: 8711-8717, 2011.

165. Albitar M: Hematopoietic cell phenotyping using circulating cell-free markers. US Patent 9,255,926 B2. Filed August 17, 2006; issued February 9, 2016.

166.Thierry A and Molina F: Analytical methods for cell free nucleic acids and applications. European Patent 2,426,217 A1. Filed September 9, 2010; issued March 7, 2012.

167. Platica O: Method of mutation detection in blood cell-free DNA using primer extension (PE) and PCR. US Patent 9,062,350 B2. Filed March 11,2012; issued June 23, 2015.

168. Hoon DSB and Taback B:DNA markers for management of cancer. US Patent 7,718,364 B2. Filed March 25, 2004; issued May 18, 2010

169. Cortese Rand Petronis A: Method for analysis of DNA methylation profiles of cell-free circulating DNA in bodily fluids. European Patent 2,483,426 A4. Filed October 1, 2010; issued April 4, 2013.
170. Schutz E, Beck J and Urnovitz H: Colorectal cancer associated circulating nucleic acid biomarkers. US Patent 2014/0303008 A1. Filed October 19,2012; issued October 9, 2014.

171. Murtaza M and Contente-Cuomo T: Quality assessment of circulating cell-free DNA using multiplexed droplet digital PCR. WO Patent 2016/168844 A1. Filed April 17, 2015; issued October 10, 2016.

172. Hoon DSB, Umetani N and Sunami E: Use of free circulating DNA for diagnosis, prognosis, and treatment of cancer. WO Patent 2006/128192 A2. Filed May 27, 2005; issued November 30, 2006.

173. Raymond CK, Lim LP and Armour CD: Methods for quantitative genetic analysis of cell free DNA. US Patent 2016/0053301 A1.Filed August 22, 2014; issued February 25, 2016.

174. Ambros V, LeeR and Fusco AP: Isolating Circulating microRNA (miRNA). US Patent 9,896,683 B2. Filed July 29, 2015; issued February 20, 2018.

175. Taylor DD and Gercel-Taylor C: Cancer-derived microvesicleassociated microrna as a diagnostic marker. US Patent 8,216,784 B2.Filed July 25, 2008; issued July 10, 2012.

176. Taylor DD and Gercel-Taylor C: Exosome-associated microRNA as a diagnostic marker. European Patent 2,806,273 B1. Filed July 25, 2008; issued September 6, 2017.

177. Croce CM, Calin GA and Volinia S: Methods for Diagnosing Pancreatic Cancer Using MicroRNAs. US Patent 2013/0324589 A1. Filed August 12, 2013; issued December 5, 2013.

178. Ditzel H, Kodahl AR: Circulating microRNA based cancer biomarkers. European Patent 3,011,058 A1. Filed December 24 , 2014; issued April 27, 2016.

179. Croce CM: MicroRNA signatures in human ovarian cancer European Patent 3,138,926 A3. Filed September 8, 2008; issued April 5, 2017.

180. Gironella I Cos M, ; Lozano-Salvatella JJ, Castells I Garangou $\mathrm{A}$ and Giraldez MD: Plasma microRNAs for the detection of early colorectal cancer, European Patent 2,944,700 B1. Filed October 10, 2012; issued October 18, 2017.

181. Zhang C, Zeng K, Zhang J, Ba Y, Chen X and Li H: Serum or plasma microRNA as biomarkers for non-small cell lung cancer. US Patent 9,388,470 B2. Filed December 14, 2009; issued July $12,2016$.

182. Croce CM, Calin GA and Volinia S: Methods for diagnosing breast cancer using MicroRNAs. US Patent 8,603,744 B2. Filed February 28, 2012; issued December 10, 2013.

183. NCT02639832, A Pilot Surveillance Study to Monitor Natural Killer Cells and Circulating Tumor Cells in Women With Previously Treated Non-metastatic Triple Negative Breast Cancer and Women With Previously Treated Non-metastatic Breast Cancer With a Confirmed BRCA Mutation, 2015.

184. NCT02626039, Characterization \& Comparison of Drugable Mutations in Primary and Metastatic Tumors, CTCs and cfDNA in MBCpatients, 2015.

185. NCT02186236, Detection of Oncogenic Tumor Mutations in the Urine and Blood of Lung and Colorectal Cancer Patients, 2014.

186. NCT02788084, Development of a Tissue-Based \& Cell Free DNA Next-Generation Sequencing Workflow, 2016.

187. NCT02883517, Cell-free Circulating DNA in Primary Cutaneous Lymphomas, 2016.

188. NCT02887612, ctDNA for Prediction of Relapse in Gastric Cancer, 2016.

189. NCT02738593, Detection Cell Free DNA in Lung Cancer Patients, 2016.

190. NCT02610218, Liquid Biopsy in Monitoring the Therapeutic Efficacy of Targeted Therapy in Advanced/Metastatic Gastric Cancer, 2015.

191. NCT02872779, Correlation Between Circulating Tumour Markers Early Variations and Clinical Response in First Line Treatment of Metastatic Colorectal Cancer (COCA-MACS), 2016.

192. NCT02443948, Circulating Cell-free Tumor DNA in the Plasma of Patients With Gastrointestinal Stromal Tumors (GIST), 2015.

193. NCT02133222, Circulating Cell-free DNA in Metastatic Melanoma Patient: Mutational Analyses in Consecutive Measurement Before and After Chemotherapy (AMMAM), 2014.

194. NCT02934984, Circulating Cell-free Tumor DNA (ctDNA) in Pancreatic Cancer, 2016.

195. NCT02784639, Comparison of KRAS/BRAF Mutational Status With Conventional Techniques and Plasma Samples Analysis, 2016.

196. NCT02036216, Circulating Cell-free DNA as a Predictive Biomarker for Hepatocelluar Carcinoma, 2014. 
197. NCT02791217, Identification of Hematological Malignancies and Therapy Predication Using microRNAs as a Diagnostic Tool, 2016.

198. NCT02928627, Clinical Significance of Hepatic and Circulating microRNAs miR-221 and miR-222 in Hepatocellular Carcinoma, 2016.

199. NCT02964351, microRNA Profiles Identification in Adeno Carcinoma Prostate Cancer, 2016.

200. NCT01541800, Circulating microRNAs as Disease Markers in Pediatric Cancers, 2012.

201.NCT02065908, Circulating MicroRNA as Biomarker of Cardiotoxicity in Breast Cancer, 2014.

202. NCT02812680, The Utility of Circulating Tumour Cells and Plasma microRNA in Esophageal Adenocarcinoma, 2016.

203. NCT01612871, Circulating miRNAs as Biomarkers of Hormone Sensitivity in Breast Cancer (MIRHO), 2012.

204. NCT01722851, Circulating miRNAs. ICORG 10-11, V2, 2012.
205. D'Agata R,Corradini R,Ferretti C,Zanoli L, Gatti M, Marchelli R and Spoto G: Ultrasensitive detection of non-amplified genomic DNA by nanoparticle-enhanced surface-plasmon resonance imaging. Biosens Bioelectron 25: 2095-2100, 2010.

206. D'Agata R and Spoto G: Surface plasmon resonance imaging for nucleic acid detection. Anal Bioanal Chem 405: 573-584, 2013.

This work is licensed under a Creative Commons Attribution-NonCommercial-NoDerivatives 4.0 International (CC BY-NC-ND 4.0) License. 